Article

\title{
Are Seat and Aisle Interferences Affecting the Overall Airplane Boarding Time? An Agent-Based Approach
}

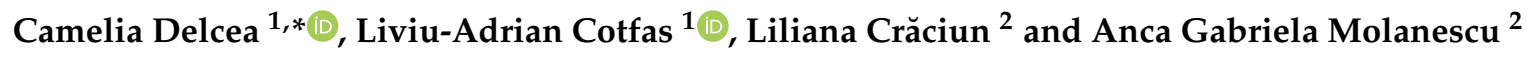 \\ 1 Department of Economic Informatics and Cybernetics, Bucharest University of Economic Studies, \\ 010552 Bucharest, Romania; liviu.cotfas@ase.ro \\ 2 Department of Economics and Economic Policies, Bucharest University of Economic Studies, \\ 010552 Bucharest, Romania; liliana.craciun@softscape.ro (L.C.); anca.molanescu@softscape.ro (A.G.M.) \\ * Correspondence: camelia.delcea@csie.ase.ro
}

Received: 18 October 2018; Accepted: 13 November 2018; Published: 15 November 2018

\begin{abstract}
Seat and aisle interferences are assumed to be linked with a prolonged boarding time along with several other aspects related to airplane boarding such as: luggage handling, luggage distribution inside the cabin, number of passengers, passengers' physique characteristics, group behavior, seat selection, aircraft occupancy, aircraft design, etc. Based on these assumptions, a series of proposed boarding methods, underlying their efficiency starting from the absence or limited presence of these types of interferences, are proposed. The present paper aims to analyze whether the different types of seat or aisle interferences do matter for the overall boarding time by considering 24 boarding methods proposed in the literature. A series of specific elements related to interferences, such as: the average waiting time, the average number of interferences based on their types, and the average number of interference-affected passengers, have been considered. Also, the presence of multiple interferences in different parts of the aircraft has been analyzed in order to offer a complete picture of the considered situation. An agent-based model in NetLogo 6.0.4, fed with values form field trials within the literature is created and used for simulations, which enables the agents to act like real passengers involved in an airplane boarding process.
\end{abstract}

Keywords: airplane boarding strategies; agent-based modelling; NetLogo 6.0.4; efficiency evaluation; sustainability; interferences

\section{Introduction}

Airplane boarding is a major process with a direct influence on an airline company's total costs. Minimizing the costs is not only contributing to the airline company's sustainability and long term performance but is also influencing the air quality as the airplanes are spending less time in the terminal and the quantity of services offered by an airport without investing in new infrastructure.

A common goal of a series of papers written in the airplane transportation area is to minimize the time needed for passengers to board the aircraft, as a major component of the airplane turnaround time [1-4]. Recent data published by Eurocontrol [5] showed that the average delay time per airplane, in Europe has increased by $9.11 \%$ in 2017 compared to 2016, reaching a level of 12.4 min of delay. Translating the average delay time into costs, by considering $\$ 53.5$ per minute as reported by $[6,7]$, it results in approximately $\$ 663.4$ for each flight made within a year. Knowing that the number of flights are over 10,190,900 flights per year [5] only in Europe, the amount generated by the airplane delay becomes considerable within the whole industry.

Thus, over time, a series of boarding methods have been proposed having the purpose of minimizing the airplane boarding time. Each of these methods have taken into account one or several of the following aspects: luggage handling and distribution in the cabin [8-13], disturbance 
caused by early or late passengers [14], passengers' individual physique characteristics [12,15], aircraft occupancy $[4,9,12,16-19]$, seat selection $[8,14]$, seat and aisle interference [1-4], group behavior [13,20], and aircraft interior design [2,21,22].

Among the causes linked directly to a prolonged boarding time, the seat and aisle interferences have been appointed as having a visibly direct impact $[3,20,23]$. In this context, some of the papers proposing new boarding methods have emphasized the fact that these methods are performing better than others as a result of reducing the seat and aisle interference [4,15,23-25]. In line with this assumptions, Iyigunlu et al. [26], p. 3, believe that "by minimizing the total expected number of seat and aisle interferences is the best way to minimize boarding time", even though the results of the study show that only on some large airplanes (e.g., Boeing 777) a reduced aisle interference can provide a better boarding time.

Considering the aisle and seat interference problem, recent research conducted by Ren and $\mathrm{Xu}$ [1] studies the presence of these interferences in boarding using six methods: random, back-to-front, outside-in, half-block, reverse pyramid, and random with music. As a result, the authors concluded that there are no seat interferences when using some boarding methods (e.g., outside-in and reverse-pyramid) and that aisle interferences are "effectively reduced if several passengers are allowed to simultaneously stow their luggage in the aisle" [1], p. 7.

On the other hand, Zeineddine [20], p. 1, argues that the best methods in the literature emphasize more on the economical and mathematical aspects of the boarding process, and "do not respect the passengers' interest to board in cliques, or do not account for the number of boarding interferences".

Thus, the present paper aims to analyze the effects aisle and seat interferences have on the overall boarding time, by focusing on the average waiting times generated by each type of interference, the number of affected passengers, and the average number of interferences encountered within a boarding process. As aisle and seat interferences are analyzed in the literature mostly when a new method is proposed, their absence or limited presence being regarded, in most of the cases, as a strong point, this paper tries to determine to which extent the interferences count in the overall boarding time. We assume that not only the presence/limited presence/absence of these types of interferences is important when proposing a new boarding method, but mostly the average number of affected passengers as some of the interferences might appear simultaneously in different parts of the aircraft.

One of the main advantages of the current study is the fact that we have considered in the analysis a number of 24 boarding methods, which will enable us to generalize the results of the study. Among the analyzed boarding methods, a series of "by seat" and "by group" methods are considered, which will offer a global view on how the interferences are manifesting in different approaches. Even more, if the results will show that a particular type of seat or aisle interference is the one responsible with an increased boarding time, this result will be helpful, in the future, when proposing a new boarding method.

In order to analyze the interferences in the boarding method context, an agent-based model in NetLogo 6.0.4. has been created, which enables us to have agents possessing human-like characteristics. In line with this purpose, the model is fed with data taken from real-field simulations as extracted from the literature.

Figure 1 presents the simulations made on an A320 airplane with 30 seat rows.

The remainder of the paper is organized as follows: Section 2 presents a brief summary of the 24 methods considered in the study along with the main types of seat and aisle interferences. Section 3 talks about the agent-based model created in NetLogo 6.0.4 and emphasizes the agents' characteristics by making an analogy between their properties and field observations. Section 4 uses the model in order to simulate the considered boarding techniques and to extract the relevant data needed in order to perform the analysis related to the link between the seat interferences and the overall airplane boarding time. The results are analyzed in Section 4, alongside data analysis and discussion. Some general conclusions are provided at the of the paper along with a list of references. 


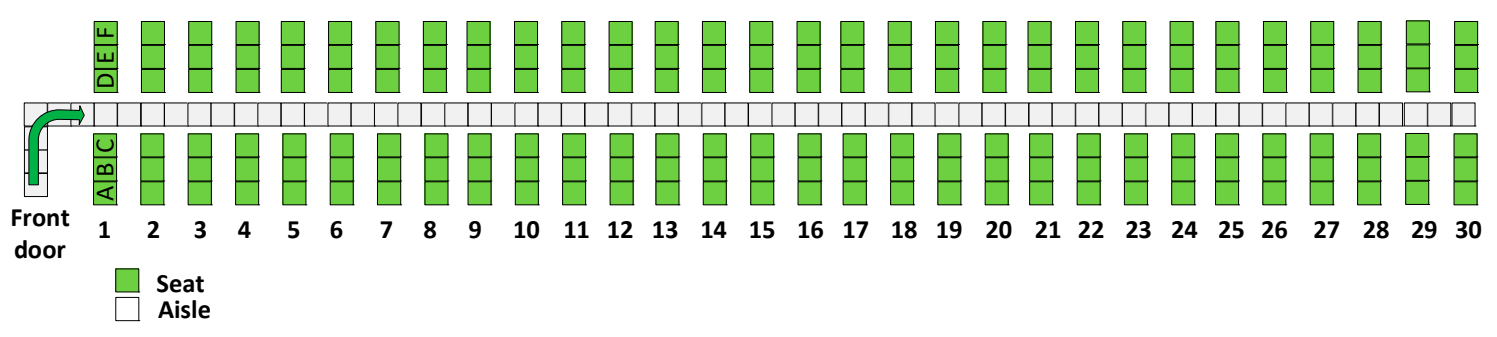

Figure 1. The considered Airbus A320 configuration.

\section{Brief Summary of Boarding Methods and Interferences}

\subsection{Boarding Methods}

A brief summary of the most well-known boarding methods is presented in Table 1 in accordance with the literature [9-11,16,27-30]. Some of the considered boarding methods are also depicted in Appendix A.

Table 1. Short description of the considered boarding methods.

\begin{tabular}{|c|c|c|c|}
\hline Classification & Boarding Method & Code & Boarding Strategy \\
\hline Random & $\begin{array}{l}\text { Random with } \\
\text { assigned seat }\end{array}$ & BS1 & $\begin{array}{l}\text { Each passenger has an assigned seat on the boarding pass. } \\
\text { The passengers are arriving in a random order for } \\
\text { boarding. Once inside the aircraft, they are searching for } \\
\text { their seat. }\end{array}$ \\
\hline \multirow{5}{*}{ By group } & Outside-in & BS2 & $\begin{array}{l}\text { Is a by group strategy, often known in the literature as } \\
\text { WilMA (Window-Middle-Aisle). According to this } \\
\text { boarding strategy, there are three groups of passengers: } \\
\text { the first one made by the passengers having seats near the } \\
\text { window (seats marked with A or F), the second group by } \\
\text { the passengers having the seats in the middle (letters B } \\
\text { and E) and the last group by the passengers with aisle } \\
\text { seats (letters C and D). The groups are invited one by one } \\
\text { inside the aircraft. }\end{array}$ \\
\hline & $\begin{array}{l}\text { Window to aisle } \\
\text { half block }\end{array}$ & BS3 & $\begin{array}{l}\text { Similar with outside-in with the only difference that the } \\
\text { seating is made first in one side of the aisle, starting from } \\
\text { the window to the aisle (seats with letter F, E and D), and } \\
\text { then in the other side of the aisle (featuring seats first near } \\
\text { the window, letter A, then middle, Letter B, and last near } \\
\text { the aisle, letter C). Thus, six boarding groups are possible. }\end{array}$ \\
\hline & $\begin{array}{l}\text { Window to aisle } \\
\text { alternate }\end{array}$ & BS4 & $\begin{array}{l}\text { Similar to the outside-in in which one is alternating the } \\
\text { groups: the passengers near one window board first, } \\
\text { e.g., having letter F on their tickets, then the passengers } \\
\text { near the other window, letter A, followed by the middle } \\
\text { seats, letters E and B, and last, passengers with aisle seats, } \\
\text { letters D and C, which conducts a total of six } \\
\text { boarding groups. }\end{array}$ \\
\hline & Reverse pyramid & BS5 & $\begin{array}{l}\text { According to this method, a portion of the window seats } \\
\text { located in the back of the airplane are loaded first, then, } \\
\text { the rest of the seats near the window and another part of } \\
\text { the middle seats are loaded. The loading continues } \\
\text { diagonally until all the passengers' groups are loaded. }\end{array}$ \\
\hline & $\begin{array}{l}\text { Reverse pyramid } \\
\text { half-zone (1) }\end{array}$ & BS6 & $\begin{array}{l}\text { A reverse pyramid loaded on half zones, also diagonally, } \\
\text { for a total of } 8 \text { boarding zones. }\end{array}$ \\
\hline
\end{tabular}


Table 1. Cont.

\begin{tabular}{|c|c|c|c|}
\hline Classification & Boarding Method & Code & Boarding Strategy \\
\hline & $\begin{array}{l}\text { Reverse pyramid } \\
\text { half-zone ( } 2 \text { ) }\end{array}$ & BS7 & Also in half-zones, but considering 10 zones. \\
\hline & Back-to-front & BS8 & $\begin{array}{l}\text { The passengers are divided into groups of about } 1 / 5 \text { of the } \\
\text { aircraft and are invited to board according to their group, } \\
\text { starting from the back of the aircraft. }\end{array}$ \\
\hline & Back-to-front mix & BS9 & $\begin{array}{l}\text { The first group invited to board is located in the rear of the } \\
\text { airplane, while the second one is in the middle. A third } \\
\text { group boards in the front followed by a group in the } \\
\text { middle-back again and a last one in the middle-front. }\end{array}$ \\
\hline & Front-to-back & BS10 & $\begin{array}{l}\text { Starts with a first group in the front of the airplane, then in } \\
\text { the front-middle, middle, middle-rear, and rear. }\end{array}$ \\
\hline & $\begin{array}{l}\text { Half-block } \\
\text { (back-to-front) }\end{array}$ & BS11 & Similar to back-to-front but on half-aisles. \\
\hline & Half-block mix (1) & BS12 & $\begin{array}{l}\text { It considers boarding first the last group on one side of the } \\
\text { aisle, then the second-back group on the other side in } \\
\text { diagonal, then, the middle group on the first side, a } \\
\text { middle-front group in the second side and last, a front } \\
\text { group on the first side. Then, it continues from the back to } \\
\text { the front for the remaining groups in the same manner. As } \\
\text { a result, } 10 \text { boarding zones are needed. }\end{array}$ \\
\hline & Half-block mix (2) & BS13 & $\begin{array}{l}\text { It is similar to applying back-to-front in one side of the } \\
\text { aisle and then applying it to the other side of the aisle, for } \\
10 \text { boarding zones, } 5 \text { on each side. }\end{array}$ \\
\hline & $\begin{array}{l}\text { By row } \\
\text { front-to-back }\end{array}$ & BS14 & $\begin{array}{l}\text { By } 6 \text { seat rows, starting from the first row of the airplane } \\
\text { and moving up row-by-row until the last row in the back } \\
\text { of the airplane is reached. }\end{array}$ \\
\hline & $\begin{array}{l}\text { By row } \\
\text { back-to-front }\end{array}$ & BS15 & $\begin{array}{l}\text { By } 6 \text { seat rows, starting from the last row of the airplane } \\
\text { and moving row-by-row until the first row in the front of } \\
\text { the airplane is reached. }\end{array}$ \\
\hline & $\begin{array}{l}\text { By half-row } \\
\text { front-to-back }\end{array}$ & BS16 & $\begin{array}{l}\text { Similar to front-to-back, but considering first one side of } \\
\text { the aisle and then the other side (by } 3 \text { seat rows at a time). }\end{array}$ \\
\hline & $\begin{array}{l}\text { By half-row } \\
\text { back-to-front }\end{array}$ & BS17 & $\begin{array}{l}\text { Similar to back-to-front, but considering first one side of } \\
\text { the aisle and then the other side (by } 3 \text { seat rows at a time). }\end{array}$ \\
\hline & Rotating zone & BS18 & $\begin{array}{l}\text { Considering five zones, the boarding order is: first group } \\
\text { in the middle of the aircraft, then the second one in the } \\
\text { front, the third one in the back, the fourth in the } \\
\text { front-middle and the fifth one in the middle-back. }\end{array}$ \\
\hline & Modified optimal & BS19 & $\begin{array}{l}\text { Consider four zones. One zone is made by all the } \\
\text { passengers having odd numbers on their tickets and } \\
\text { placed in one side of the aircraft. The second group has the } \\
\text { same rules, but is located on the other side of the airplane. } \\
\text { The thirst one has the even numbers on the boarding } \\
\text { tickets in the first side of the aisle, while the last group has } \\
\text { the even numbers on the other side of the aisle. }\end{array}$ \\
\hline & Non-traditional & BS20 & $\begin{array}{l}\text { In general, this is composed of three equal zones } \\
\text { (depending on the side of the airplane) and a fourth zone } \\
\text { which is considerably smaller (formed by } 3 \text { rows). } \\
\text { The passengers of the smaller zone located in the } \\
\text { middle-back side of the aircraft are boarded first, followed } \\
\text { by the ones in the middle zone, then front zone and last, } \\
\text { the rear zone. }\end{array}$ \\
\hline
\end{tabular}


Table 1. Cont.

\begin{tabular}{|c|c|c|c|}
\hline Classification & Boarding Method & Code & Boarding Strategy \\
\hline \multirow[t]{4}{*}{ By seat } & $\begin{array}{l}\text { Back to front by } \\
\text { seating order }\end{array}$ & BS21 & $\begin{array}{l}\text { The first occupied seat is located in the last row of the } \\
\text { aircraft near one of the windows, while the second one is } \\
\text { near the other window. After that, the middle seats in the } \\
\text { last row are occupied in one side and then in the another } \\
\text { side of the aisle, followed by the aisle seats. Once the last } \\
\text { row is complete, the second-last row is filled-in based on } \\
\text { the same rule. The last passenger boarding will have an } \\
\text { aisle seat in the first row of the airplane. }\end{array}$ \\
\hline & Descending order & BS22 & $\begin{array}{l}\text { It completes seat-by-seat the places near one window } \\
\text { starting from the back of the airplane until the front and } \\
\text { then, the seats near the other window are filled-in } \\
\text { seat-by-seat also from the back to the front. One will } \\
\text { proceed in the same way with the middle and then with } \\
\text { the aisle seats. }\end{array}$ \\
\hline & Steffen & BS23 & $\begin{array}{l}\text { Similar to a descending order with the only difference } \\
\text { being that the window seats are boarded seat-by-seat first } \\
\text { on the odd rows, them on the even rows, and after that the } \\
\text { middle seats on the odd rows, middle seats on even rows, } \\
\text { aisle seats on odd rows, and last, even seats on even rows. }\end{array}$ \\
\hline & Variation in Steffen & BS24 & $\begin{array}{l}\text { Similar to the descending order with the only difference } \\
\text { that the window, middle and aisle seats are boarded } \\
\text { seat-by-seat only on the odd rows until all the odd rows } \\
\text { are filled in. After that, the scheme continues in the same } \\
\text { manner for the even rows. }\end{array}$ \\
\hline
\end{tabular}

\subsection{Types of Interferences}

Two main types of interferences are acknowledged in the literature: aisle and seat interferences $[20,31,32]$. The aisle interference is defined as the situation in which a passenger blocks the aisle during the boarding time. This situation arises, in most of the cases, due to the fact that one of the passengers needs time to store the luggage in the overhead compartment. In some cases, the aisle interference may be due to the fact that a passenger needs to enter the row and occupy his, but this is not generally acknowledged in the literature, thus, we shall not consider this situation within this paper [20]. As for the time needed to un-block the aisle in this type of interference, Qiang et al. [32] determined a time of $25 \mathrm{~s}$, while Schultz [31] established a time of $13.9 \mathrm{~s}$. Considering Kierzkowski and Kiesel's paper [4], one can distinguish between the time needed by a passenger to store cabin luggage, also seen as a big hand luggage, and to place outwear, often seen as similar to small hand luggage. The authors present in their paper the cumulative distribution functions for both types of luggage. This approach can be useful in agent-based modelling and simulation as it offers the possibility to endow the agents' with different values for the storing luggage property, bringing their behavior closer to real-life passengers.

The seat interference, also known as the "row interference", occurs when a passenger has to wait for one or two passengers seated on the same row to clear his path to his assigned seat. In this case, several seat interference situations may appear as they are presented in Figure 2.

In type 1 seat interference, the passenger having the seat near the window is occupying the aisle for a longer period of time than in the other three cases of seat interference as he needs to wait for the two passengers located on the same row on the middle and aisle seat to clear his path. A total of nine movements are needed in this case for the two passengers to step out of the row, for the passenger with a window seat to reach his place and for the two passengers to re-enter the row and take their initial sitting positions. According to the field trial conducted within the literature it has been established that type 1 seat interference blocks the aisle for an average time of $22 \mathrm{~s}$, ranging between [20, 26] s [31]. 


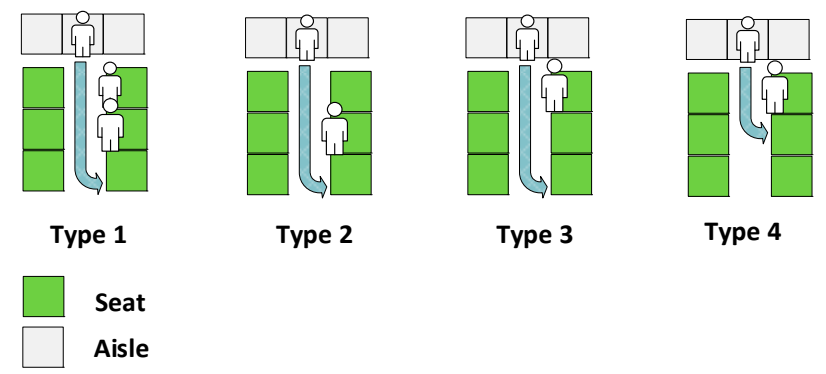

Figure 2. Types of seat interferences.

Type 2 seat interference appears when a passenger needs to sit near the window, but the middle seat is occupied. In this case, the passenger located in the middle seat needs to exit the row, wait for the passenger with the seat near the window to take his place and then to return to his initial position. A number of 7 movements are required in this case, which makes the time needed to unblock the aisle to be equal to $11 \mathrm{~s}$, ranging in $[10,13] \mathrm{s}[31]$.

Type 3 and 4 seat interferences refer to the situation in which a person is seated near the aisle and another passenger needs to take the window or middle seat. Even though the two type of seat inferences require a different number of moves until both passengers are seated, namely five and four movements, the time associated to these two interferences is equal as the additional move present in type 3 is made by the passenger located near the window inside the row, thus, it is not affecting the overall aisle blocking time. Field trials have shown similar results in terms of time: Schultz [31] found an average interference time of $10 \mathrm{~s}$, ranging between $[9,13] \mathrm{s}$, while Qiang et al. [32] reported an interference time of $7 \mathrm{~s}$. The small difference among the two studies regarding field trials may be due to the fact that Schultz [31] also considers a delay time that is needed for a passenger to sit equally on an average of $3 \mathrm{~s}$, ranging between $[2,4] \mathrm{s}$, which, when extracted from the seat interference time, gives the same value as reported by Qiang et al. [32].

\section{Agent-Based Modeling in NetLogo}

The basis of the agent-based modeling (ABM) is the agent, a computational entity that possesses the state variables and values that enable it to act similar to the entities it models [33]. Due to its properties, such as: autonomy, social ability, responsiveness, reactiveness, adaptability, mobility, veracity and rationality, each agent can imitate the actions of real passengers when facing an airplane boarding process $[26,33,34]$. Some of the main advantages of using NetLogo over other agent-based modelling software in the market are highlighted in [28,34].

Creating an agent-based model in NetLogo offers a series of benefits that derive from the principles of agent-based modelling, while offering an easy way to write a code section and a graphical interface that enables a proper observation of an agents' behavior at each moment of time.

Over time, the ABM in NetLogo has served as the primary tool when analyzing different entities behaviors in areas such as: transportation [35-38], healthcare [39-41], social sciences [42], environmental sciences [43,44] or emergency situations behavior and crowd movements [45-56].

In the following, an agent-based model has been created in NetLogo 6.0.4 in order to simulate passenger behavior when different boarding strategies are applied, with an accent on the total boarding time, types of interferences, affected persons, and time lost due to interferences.

\subsection{Methodology and Model's Parameters}

The model considers an aircraft consisting only of an economy class $[11,12,17,19]$. The number of seats located on each row is six, while the number of seat-rows is configurable, making the model easily adaptable to different desired simulation situations.

Two types of agents are encountered in the model: the turtles representing the passengers engaged in the boarding process and the patches representing either part of the aisle or seats in the aircraft. 
Depending on the type of agent, different properties are possible. For example, the patches possess fewer characteristics than the turtle agents, mainly related to their seat-row position and whether they are part of the aisle, free seat, or occupied seat. On the other hand, the turtle agents have their own speed while advancing down the aisle. They either carry or do not carry luggage, that luggage storage will need a particular storing time. They can be seated or moving. They have an assigned seat row and an assigned seat number. While moving down the aisle, they can adapt the speed based on the agents in front of them and are unable to overpass another agent located on the aisle. Thus, when an agent is engaged in either taking its seat (facing a seat interference) or is loading its luggage in the overhead compartment, all the agents located behind it need to adapt their speed, in the first place by lowering their speed. Also, their speed can reach zero as the agent needs more time to store the luggage or to take its place, sometimes producing a mass disturbance by reducing the speed of several agents in the aisle down to zero. All these agents, which are not able to advance in the aisle due to an interference situation, are considered affected passengers and they will be counted for each type of considered interference.

As a result, each agent can report the type of seat or aisle interference it is engaged with. For the seat interference, once arrived near the assigned row, the agent's speed is reduced down to zero and it is able to examine the state of the seats located near it. Based on its seat position and the other two seats' state, the agent will report the seat interference it is facing through the variable "seating-interference-type". Also, in each simulation moment, one can observe the agent's state by opening an agent monitor and read its properties; as shown in Figure 3.

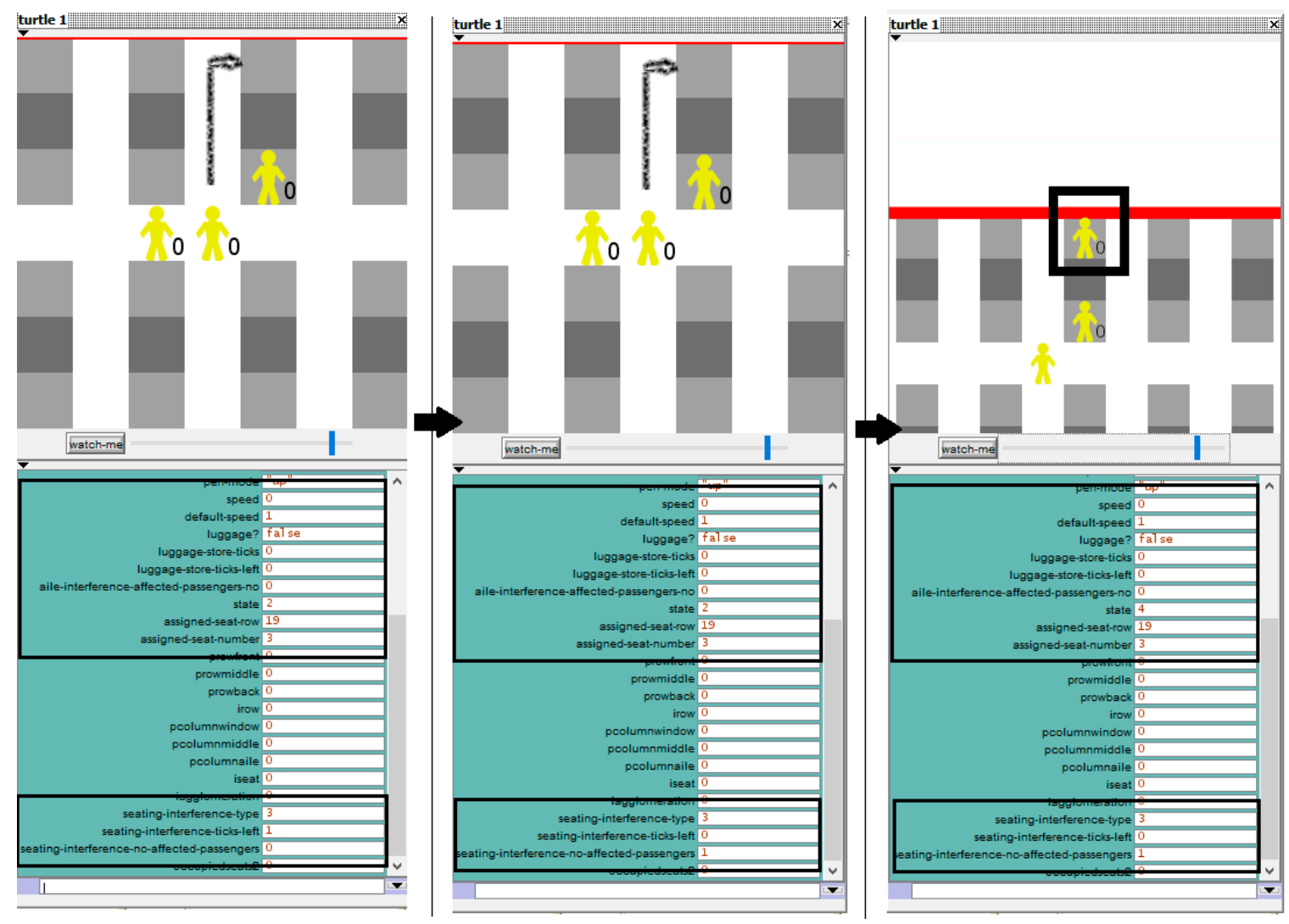

Figure 3. Example of changing properties for turtle 1 during simulation process.

Also, there might be a situation in which an agent is engaged first in an aisle interference, followed right after by a seat interference of a particular type. In this case, the affected passengers may vary due to different dynamics within the aisle strictly related to other passengers' rules of behavior (e.g., storing luggage or other seat interferences they are engaged with), the model being able to properly identify 
which of the affected passengers are belonging to each interference type and properly add their number to the total number of affected passengers within the whole aircraft.

All the times considered for boarding, advancing down the aisle and the interference time generated by each type of interference are in line with the values determined in the literature through field trial and are presented in Section 2.2.

Some of the agents' properties have been kept from our previous model for one-door boarding as presented in [28] and some new features have been added by incorporating the field trials data from $[4,12,31,32]$ related to luggage storage and different seat and aisle interferences.

As the time in NetLogo is represented through "ticks" it has been established based on $[29,31]$ that it counts for $3.7 \mathrm{~s}$ in real life. Thus, the discussion in the rest of the paper will be conducted in terms of ticks. In case one, it is interested in the real time, which can be simply computed by multiplying the ticks with the mentioned constant.

\subsection{Modeling the Boarding Process}

The boarding process consists of giving the proper rules to the agents as once they arrive at the front door to be able to proceed down the aisle until the allocated seat. Depending on the chosen method at the beginning of each simulation, which can easily be selected by using the "Boarding-method" slider-Figure 4, the agents with different seating positions arrive to be boarded.

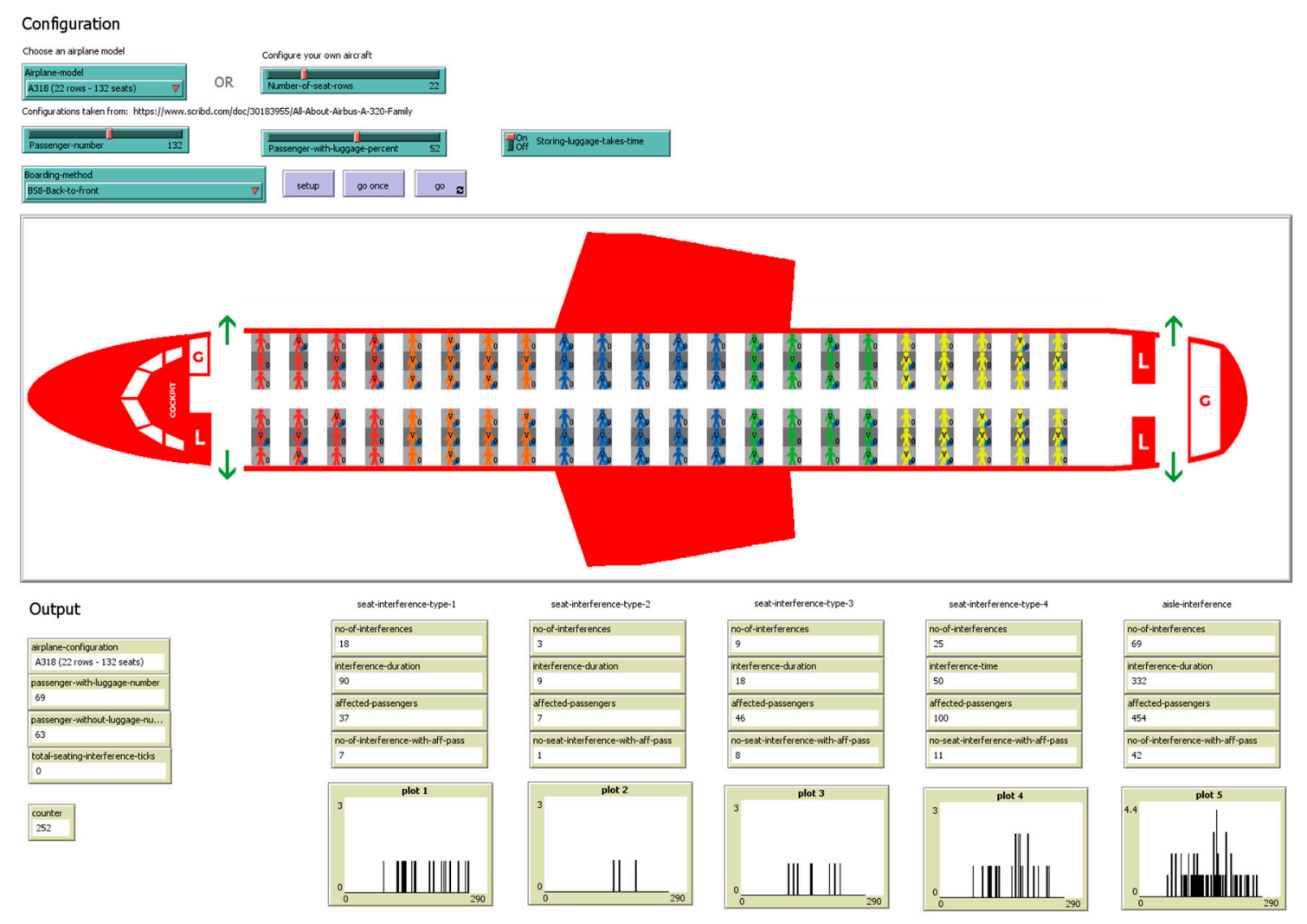

Figure 4. Agent-based model in NetLogo 6.0.4.

A series of monitors are available in which the number of seat or aisle interferences are reported along with their duration, number of affected passengers, and the number of interferences with affected passengers. Also, five histograms, for each type of interference, are available, which can be useful if one wants to observe the parallel interferences within the aircraft in every moment of time. 


\section{Data Analysis and Discussions}

The simulations have considered the situation in which the A320 airplane is fully-boarded, having 180 passengers. It begins with the with the idea that all of them are carrying at least one small bag, which could also represent some outwear, inside the aircraft. All of the 24 methods presented above have been considered, even though, it is known from the literature that some of them are producing not so good results in terms of boarding time, such as all the methods considering the front-to-back boarding approach. We have decided to keep as many methods as possible in order to have a complete picture over the boarding process, in order to decide whether the interferences have a significant impact over the boarding process time.

Figure 5 below provides a simulation snapshot of the boarding process through a random with assigned seats method. A series of videos for each of the 24 methods can be additionally accessed at the following link: https:/ / github.com/liviucotfas/ase-2018-sustainability-interferences.

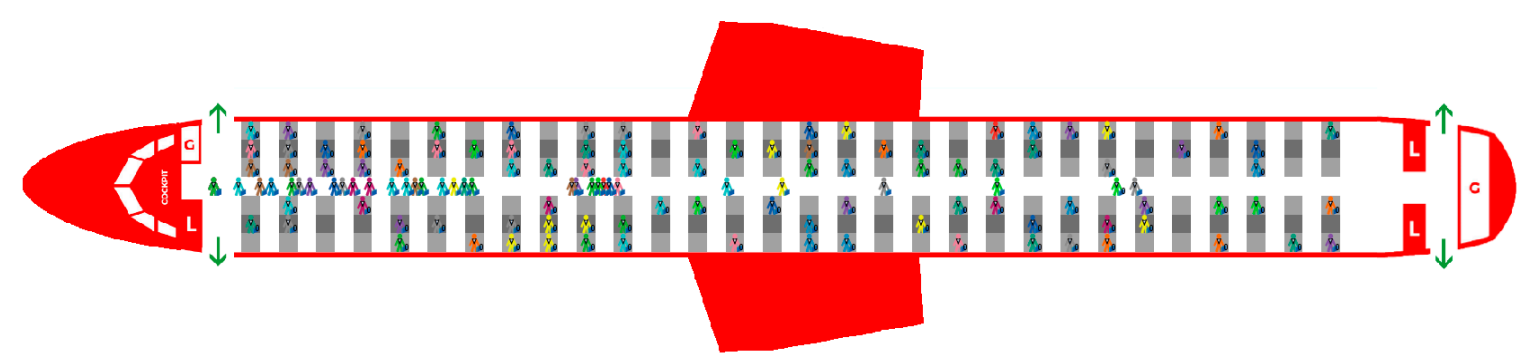

Figure 5. Snapshot of a simulation with $t=280$ ticks, random with assigned seats situation.

The analysis has been carried out first of all in terms of seat and aisle interference. Each of the 24 methods has been run 400 times and the average values gathered through these simulations are presented in Tables 2 and 3.

Based on these data it can be observed that the method with the smallest boarding time expressed in ticks is by half-row back to front (343 ticks), followed by descending order (355 ticks), half-block mix 1 (373 ticks), half-block back-to-front (379 ticks), variation in Steffen (383 ticks) and Steffen (385 ticks), reverse pyramid half zone 2 (390 ticks) and back to front (396 ticks). On the other verge, the methods such as by row front-to-back ( 1028 ticks) or by half-row front to back ( 873 ticks) have scored the highest boarding time.

\subsection{Data Analysis in Terms of Seat Interferences}

As expected, there are a series of methods with zero seat interferences: WilMA (including WilMA half-block and WilMA alternate), reverse pyramid (including half zone 1 and 2), back-to-front by seating order, descending order, Steffen, and variation in Steffen. The absence of seat interferences derives right from their boarding rules.

By analyzing the numbers in Table 3 it can be seen that even though the boarding method back to front by seating order was expected not to have any seat interferences, type 2 and type 4 are encountered in a small number of cases. This is due to the fact that while two passengers having the seats in the same row, which are finding themselves consecutively in a queue, are placing their luggage in the overhead compartment, it might happen that the passenger located in the middle or in the aisle to store faster its luggage, which will enable it to take its seat. The other passenger, which needs more time to store the luggage will take the seat after the passenger located behind him has done this, conducting an involuntary seat interference. This situation might also arise in real life situations due to the fact that the free space in the overhead compartment is not located just above the row of seats, which can facilitate small interchanges among passengers and therefore, some type 2 and type 4 seat interferences may appear. As seen from Table 3 these cases are quite rare within a boarding process, having on average just one seat interference of each type within a simulation. 
In the following, we shall exclude the methods scoring zero for the seat interferences from the analysis as this type of interference is not affecting them and we shall return to them in the next subsection dedicated to aisle interferences.

Considering the other methods which have scored non-zero values for the seat interferences, it can be observed that the method by half row from back to front (BS17) scored the best boarding time among all the methods even though the values for the seating interferences are not zero. Running the model of this method several times, it can be observed that type 1 seat interference can be encountered only once in all the simulations, while the number of affected passengers is the same: 90 passengers in this case (as all the simulations are done on 180 passengers). This situation occurs due to the fact that once the first half of the aircraft (located in one side of the aisle) is full, the passengers located in the second half of the aisle need to wait for the last passenger from the first half to take its seat in order to access the aisle.

Focusing only on seat interference type 1 it can be observed that the methods that succeed have smaller numbers of this type of interference (e.g., BS17, BS11, BS12). They also score better values in terms of boarding time. This is not generally available, as BS19 is scoring a low number of interferences with affected passengers (11 interferences on average), but is still having a higher overall boarding time.

Thus, we can try to analyze the number of affected passengers for this type of interference and one might notice that the number of affected passengers do count in this case. It can be seen that even through BS11, BS12 and BS19 have the same average number of type 1 seat interferences on average, the number of affected passengers is greater in the case of BS19 (365 passengers) than in the case of BS11 (175 passengers) and BS12 (132 passengers)—see Figure 6.

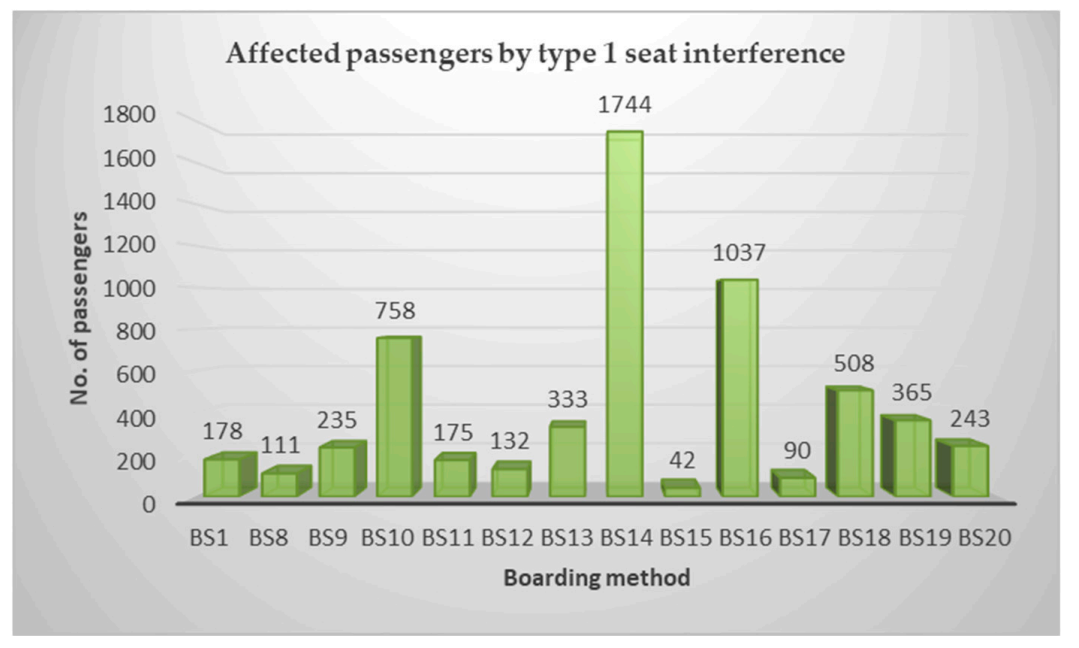

Figure 6. No. of affected passengers for each type of boarding method considering type 1 seat interference.

Moving forward to type 2 seat interference, the average number of interferences with affected passengers are almost the same over all the boarding methods, ranging between six and ten interferences on average in a boarding simulation. Thus, the type 2 seat interference might only be important in terms of affected passengers. Thus, considering the passengers' number, the situation is similar to the one encountered in the case of type 1 seat interference for the methods having a front-to-back approach, namely BS10, BS14 and BS16 - see Figure 7.

Also, regarding the BS17 method it can be seen that it has the smallest number of affected persons, namely eight passengers. Considering the number of type 2 interferences for this method, 7 interferences, it can be said that on average, the type 2 interference in BS17 is affecting just one single passenger located on the aisle. This is also the smallest value recorded over all the considered methods in the case of type 2 seat interference. 
Type 3 and 4 seat interferences are producing the same delay time, thus, even though we have measured them individually, we can analyze them together. It can be observed that the average number of interferences for type 4 are almost twice than the average number of type 3 interferences for almost all the methods. The smallest number of interferences with affected passengers is scored by BS17 in both type 3 and type 4 .

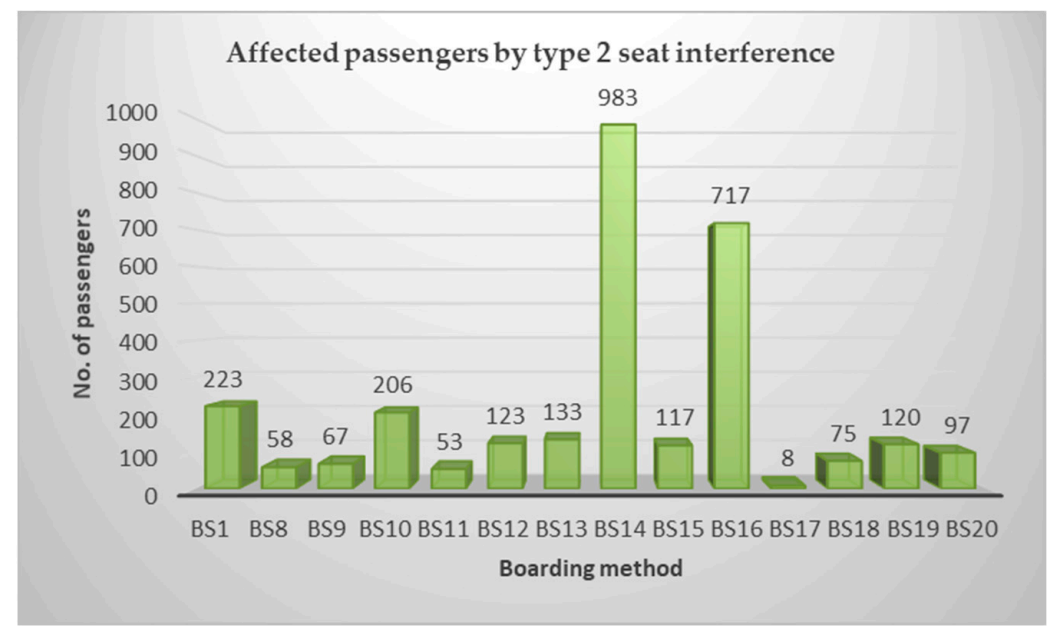

Figure 7. No. of affected passengers for each type of boarding method considering type 2 seat interference.

Taking into account the cumulative number of interferences with affected passengers, the interval is small across the methods, starting from 17 interferences in the case of BS17 and getting to at most 34 interferences in the case of BS16.

As for the cumulative number of affected passengers (Figure 8), relevant differences can be noticed across the methods, having almost the same distribution as type 1 and type 2, namely the front-to-back methods (BS10, BS14 and BS16) score higher values, even in this case.

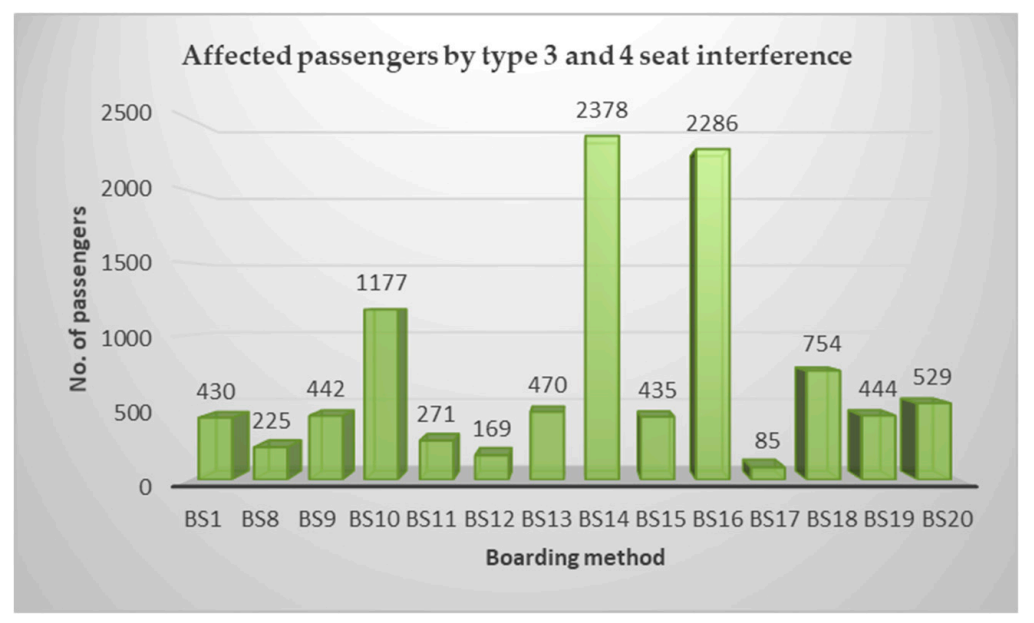

Figure 8. No. of affected passengers for each type of boarding method considering type 3 and 4 seat interference.

Considering all the seat interferences from above, one can notice that the number of interferences only presents one side of the story, while the number of affected persons makes a difference. One can think that, in the case of the methods that score good boarding times, the average number of affected passengers per number of interferences is smaller than in the other methods' case, this might happen due to the presence of parallel seat interference across the airplane. Thus, we shall discuss this in some of the following subsections. 
Table 2. Simulated data for boarding methods BS1-BS12.

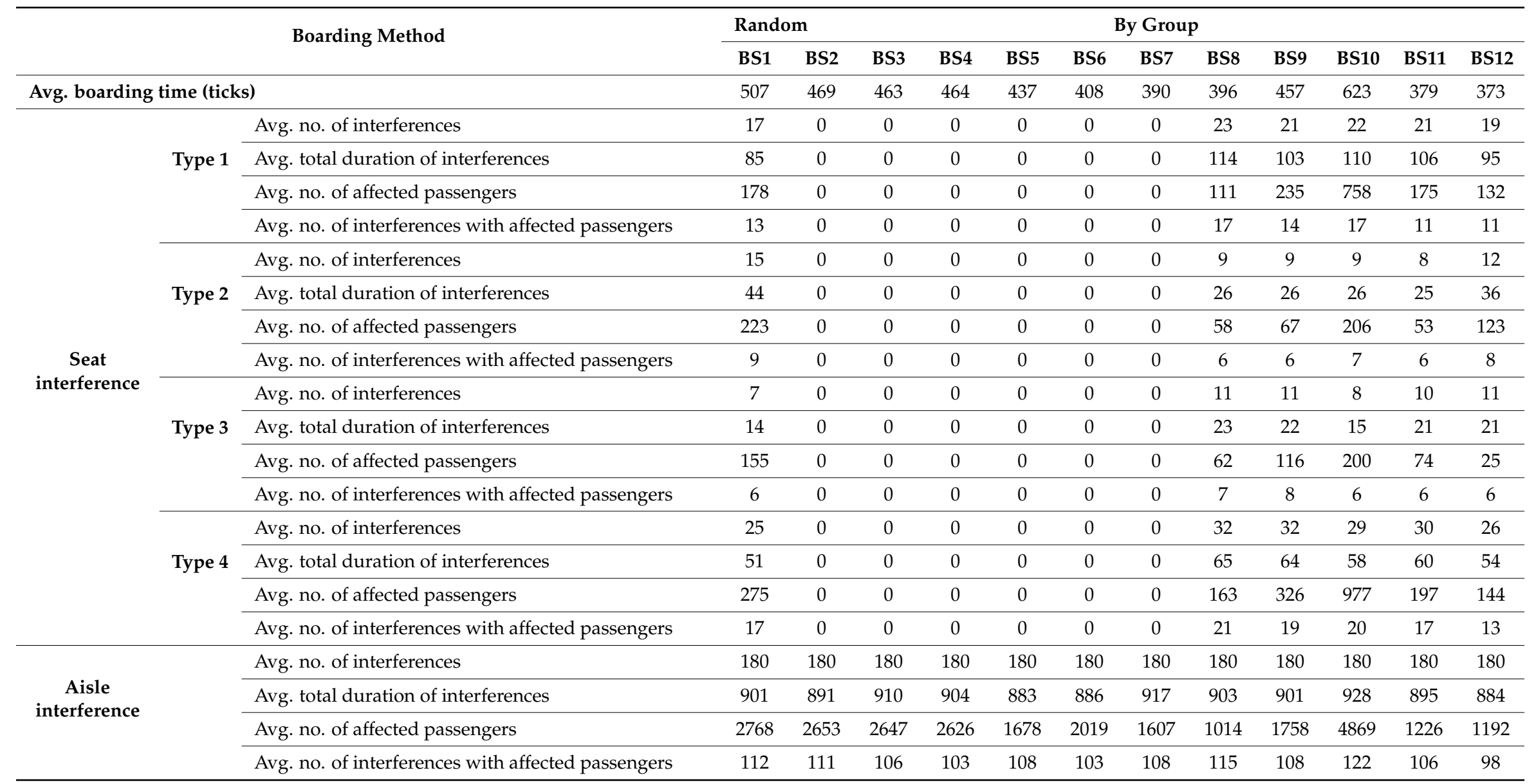


Table 3. Simulated data for boarding methods BS13-BS24.

\begin{tabular}{|c|c|c|c|c|c|c|c|c|c|c|c|c|c|c|}
\hline \multirow{2}{*}{\multicolumn{3}{|c|}{ Boarding Method }} & \multicolumn{8}{|c|}{ By Group } & \multicolumn{4}{|c|}{ By Seat } \\
\hline & & & BS13 & BS14 & BS15 & BS16 & BS17 & BS18 & BS19 & BS20 & BS21 & BS22 & BS23 & BS24 \\
\hline \multicolumn{3}{|c|}{ Avg. boarding time (ticks) } & 449 & 1028 & 464 & 873 & 343 & 537 & 501 & 531 & 416 & 355 & 385 & 383 \\
\hline \multirow{16}{*}{$\begin{array}{c}\text { Seat } \\
\text { interference }\end{array}$} & \multirow{4}{*}{ Type 1} & Avg. no. of interferences & 19 & 21 & 18 & 15 & 21 & 21 & 19 & 18 & 0 & 0 & 0 & 0 \\
\hline & & Avg. total duration of interferences & 96 & 105 & 91 & 75 & 103 & 105 & 94 & 91 & 0 & 0 & 0 & 0 \\
\hline & & Avg. no. of affected passengers & 333 & 1744 & 42 & 1037 & 90 & 508 & 365 & 243 & 0 & 0 & 0 & 0 \\
\hline & & Avg. no. of interferences with affected passengers & 11 & 19 & 8 & 15 & 1 & 17 & 11 & 14 & 0 & 0 & 0 & 0 \\
\hline & \multirow{4}{*}{ Type 2} & Avg. no. of interferences & 9 & 10 & 12 & 11 & 9 & 7 & 8 & 11 & 2 & 0 & 0 & 0 \\
\hline & & Avg. total duration of interferences & 28 & 30 & 36 & 32 & 28 & 21 & 25 & 34 & 6 & 0 & 0 & 0 \\
\hline & & Avg. no. of affected passengers & 133 & 983 & 117 & 717 & 8 & 75 & 120 & 97 & 25 & 0 & 0 & 0 \\
\hline & & Avg. no. of interferences with affected passengers & 7 & 9 & 9 & 10 & 7 & 7 & 6 & 9 & 1 & 0 & 0 & 0 \\
\hline & \multirow{4}{*}{ Type 3} & Avg. no. of interferences & 9 & 12 & 12 & 11 & 9 & 12 & 11 & 11 & 0 & 0 & 0 & 0 \\
\hline & & Avg. total duration of interferences & 18 & 24 & 24 & 21 & 18 & 24 & 21 & 21 & 0 & 0 & 0 & 0 \\
\hline & & Avg. no. of affected passengers & 49 & 531 & 179 & 698 & 5 & 148 & 56 & 122 & 0 & 0 & 0 & 0 \\
\hline & & Avg. no. of interferences with affected passengers & 5 & 7 & 9 & 8 & 5 & 8 & 7 & 6 & 0 & 0 & 0 & 0 \\
\hline & \multirow{4}{*}{ Type 4} & Avg. no. of interferences & 30 & 29 & 31 & 28 & 31 & 33 & 31 & 32 & 2 & 0 & 0 & 0 \\
\hline & & Avg. total duration of interferences & 55 & 58 & 61 & 56 & 63 & 65 & 62 & 65 & 4 & 0 & 0 & 0 \\
\hline & & Avg. no. of affected passengers & 421 & 1847 & 256 & 1588 & 80 & 606 & 388 & 407 & 1 & 0 & 0 & 0 \\
\hline & & Avg. no. of interferences with affected passengers & 17 & 22 & 14 & 26 & 12 & 21 & 20 & 22 & 1 & 0 & 0 & 0 \\
\hline \multirow{4}{*}{$\begin{array}{c}\text { Aisle } \\
\text { interference }\end{array}$} & & Avg. no. of interferences & 180 & 180 & 180 & 180 & 180 & 180 & 180 & 180 & 180 & 180 & 180 & 180 \\
\hline & & Avg. total duration of interferences & 896 & 905 & 900 & 917 & 906 & 893 & 900 & 889 & 895 & 916 & 893 & 911 \\
\hline & & Avg. no. of affected passengers & 2019 & 11846 & 2015 & 9494 & 750 & 2968 & 2400 & 2195 & 1700 & 563 & 1255 & 1152 \\
\hline & & Avg. no. of interferences with affected passengers & 102 & 137 & 108 & 149 & 86 & 120 & 111 & 113 & 106 & 7 & 23 & 20 \\
\hline
\end{tabular}




\subsection{Data Analysis in Terms of Aisle Interferences}

Aisle interference is present in all the boarding method simulations as all 180 passengers engaged in the boarding process are carrying with them inside the aircraft at least one small luggage.

Some of the by-seat methods (such as BS22, BS23 and BS24) score relatively small values for the average number of interferences with affected passengers (7,23 and 20 interferences). Even though the number is small, when looking for the actual average number of affected passengers (see Figure 9) it can be seen that, at least for BS23 and BS24, it is comparable with other boarding methods which are scoring higher boarding times, such as BS5. Even though these three methods have few aisle interferences the impact of these interferences is high within the whole boarding process as the average number of affected passengers per number of interferences is 80,55 and 58 , which is greater than almost all the other methods (except for BS14 and BS16, which are in a completely different situation, having a great number of affected persons and a great number of interferences, which, on average is conducting to a great number of affected persons per interactions).

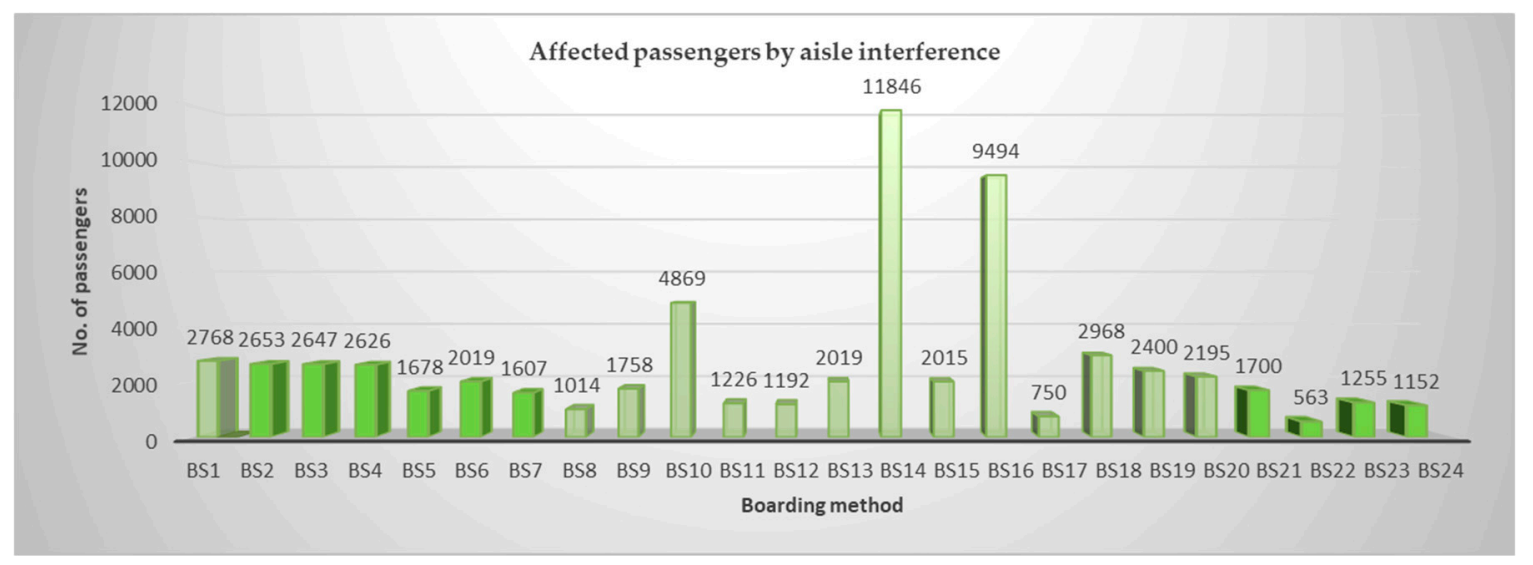

Figure 9. No. of affected passengers for each type of boarding method considering aisle interference.

In Figure 9 we have marked with an intense green the methods without seat interferences. It can be seen that the average number of affected passengers are comparable with the other boarding methods (except for the front-to-back methods). Thus, even though the seat interferences are missing for these methods, the aisle interferences are affecting a great number of passengers.

\subsection{Data Analysis in Terms of Both Seat and Aisle Interferences}

Based on the observations made above regarding the two types of interferences, we might think that the lack of seat interference is creating advantages to some boarding methods such as: BS2-BS7 and BS21-BS24. This is just partially true as seat interferences are not offering the complete picture, due to the fact that these methods also face aisle interference. The aisle interference for the methods without seat interferences is manifested in two ways: first of all through the number of affected passengers, which is comparable to the other methods that are not facing seat interferences, and through the average number of aisle interferences with affected passengers, which is greater for the BS2-BS7 methods and smaller for the BS21-BS24. Having a smaller number of interferences with a higher number of affected persons is not a good situation for the BS21-BS24 methods as the overall passengers affected by each aisle interference is high, conducting to an increase in the overall boarding time, losing in this way the advantage brought on by zero seat interferences. At a bigger scale, the whole result in terms of time is not bad for BS21-BS24. Thus, one might believe that having a higher number of interferences with a comparable number of affected passengers might work worse in terms of boarding time, and this is the case for BS2-BS6, as the overall boarding time is higher than other methods. The only method that seems not to be affected by this "rule" is BS7, which, even though has 108 interferences with affected persons and a number of 1607 affected persons, it succeeds in 
scoring good boarding times. From here, one might think that there might be more than seat and aisle interferences when analyzing the overall boarding time and we shall discuss in the next section the boarding rules that govern the boarding process.

As for the other methods (BS1, BS8-BS20), which are already affected by the seat interferences, a higher number of aisle interferences will add time to the overall boarding time, thus, making the cumulative influence even bigger.

\subsection{Data Analysis in Terms of Boarding Rules}

Starting from the idea that there might be more elements influencing the overall boarding time, we thought that it might worth spending some time and investigating in how the boarding time is evolving when no seat interferences are considered nor aisle interferences.

Thus, we have re-run the model 400 times on each method and we have extracted the average boarding time, which depend on the methods' rules. This time, in the model, the passengers walking down the aisle, are not carrying with them luggage. When arriving to their seat they are just jumping on it, without losing time for seat interferences. On the aisle, the same rules apply as they still cannot overpass the passengers in front of them and they must adapt the speed based on their own speed and the speed of the passenger located in front of them.

By isolating the model through extraction of the by seat and by aisle interferences, it can be seen that some methods are just performing better on the same type of aircraft and with the same number of passengers. It can also be observed that all back-to-front methods are reaching smaller values for the overall boarding time (e.g., BS8, BS9, BS11, BS12, BS15, BS17, BS21-see Figure 10). As in this case the boarding time depends only on the rules given by each method, one can conclude that the overall boarding time depends also on the boarding rules. Considering the back-to-front methods and running the model step-by-step it can be seen that multiple parallel seating situations are possible, thus when proposing a new boarding method one might include the back-to-front rule approach.

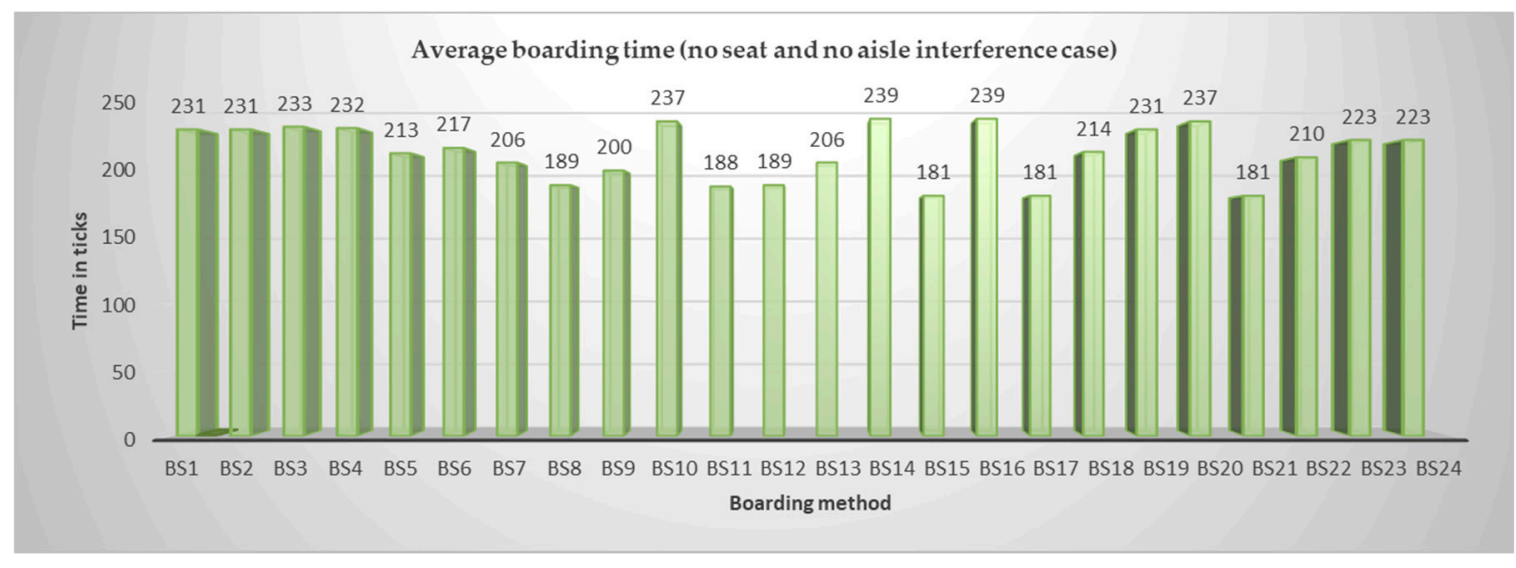

Figure 10. Boarding time in ticks for the no seat and no aisle interference situation.

\subsection{Cumulative Data Analysis}

After concluding that the boarding rules matter, we have thought to go further and to extract the influence of the seat interference on the boarding time, by eliminating the luggage from the simulations. The values in Figure 11 have been obtained in this case. 


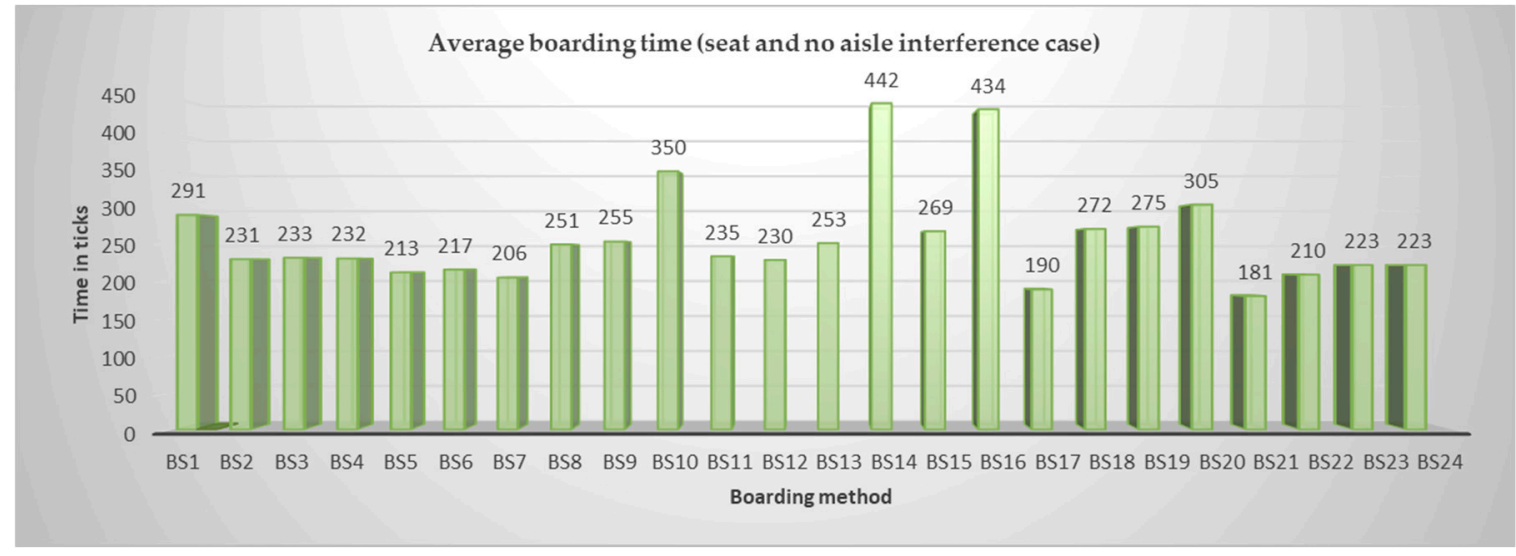

Figure 11. Boarding time in ticks for the seat and no aisle interference situation.

Comparing the values with the ones obtained in Figure 10, it can be seen that no time has been added for the methods whose rules are already considering the existence of no seat interferences. As for the other methods (e.g., BS1, BS8-BS20) the time from seat interferences is considerable in the overall boarding time-see Figure 12—especially for the front-to-back methods.

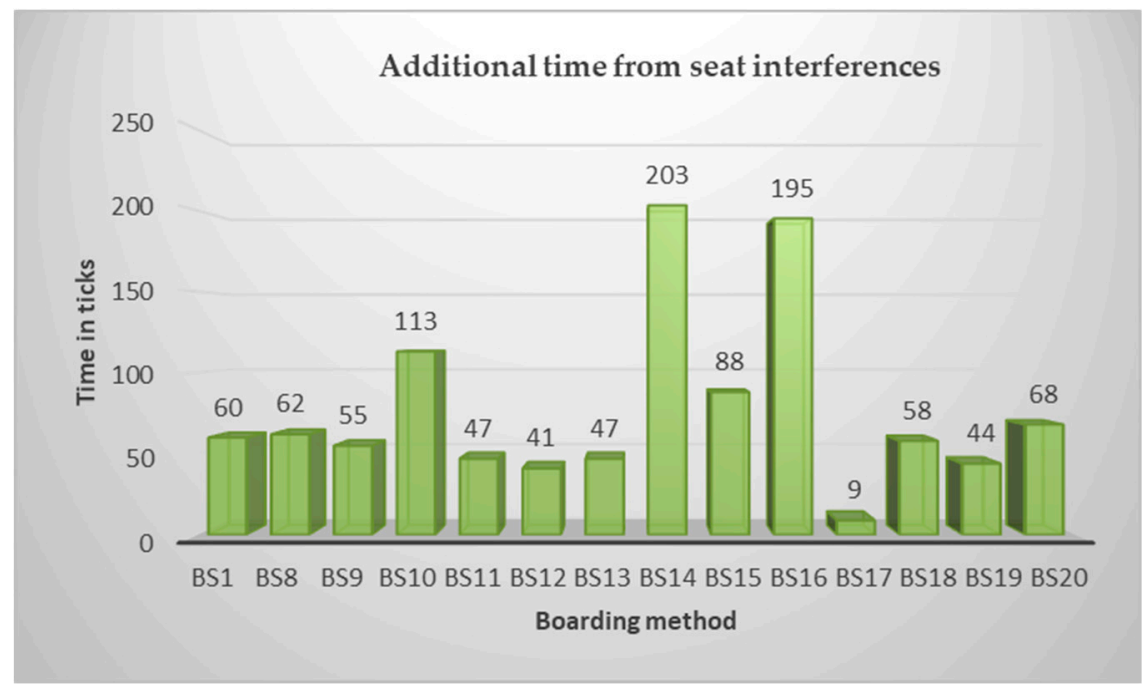

Figure 12. Additional time from seating interference.

It can be noticed that for the BS17 method, which is not targeting a reduced seat interference, the additional time produced by the seat interferences is just nine ticks, even though on a boarding process, on average, there are 25 seat interferences when using this method (according to the data in Table 3). Thus, the following question arises: how is it possible to have a delay of only nine ticks in a situation with 25 seat interferences? The answer is related to the presence of parallel seat (and/or aisle) interferences and this can be seen from the histogram of all the seat interferences for BS17 in comparison to the histogram for BS14-Figure 13.

Proceeding in the same way, we have extracted the overall boarding time for the seating interferences situation (data in Figure 11) from the data in Tables 2 and 3 regarding the overall boarding time and the data in Figure 14 has been determined. 

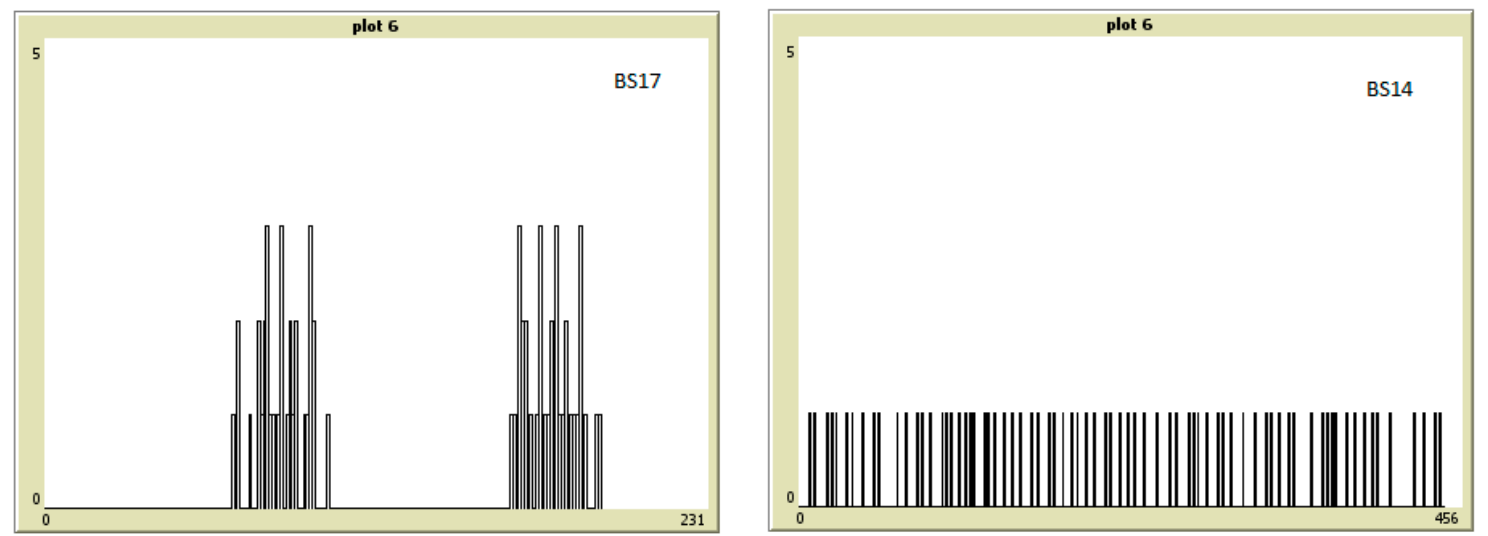

Figure 13. The histogram for the number of seat interferences (BS17 vs. BS14 method).

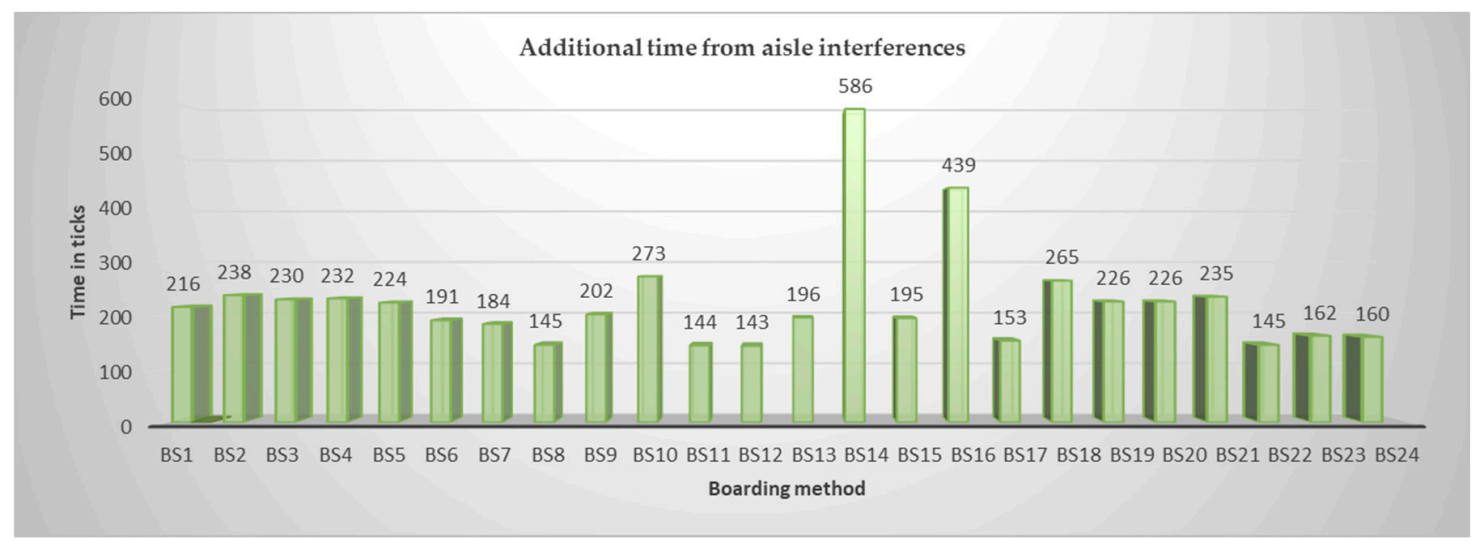

Figure 14. Additional time from aisle interference.

It can be observed that even the aisle interferences are adding significant time to the overall boarding time and we are not referring just to the front-to-back methods.

Comparing the histograms in the case of both seat and aisle interferences, it can be observed that more parallel interferences are encountered in BS17 than in BS14-Figure 15, which might have an impact on the overall boarding time.
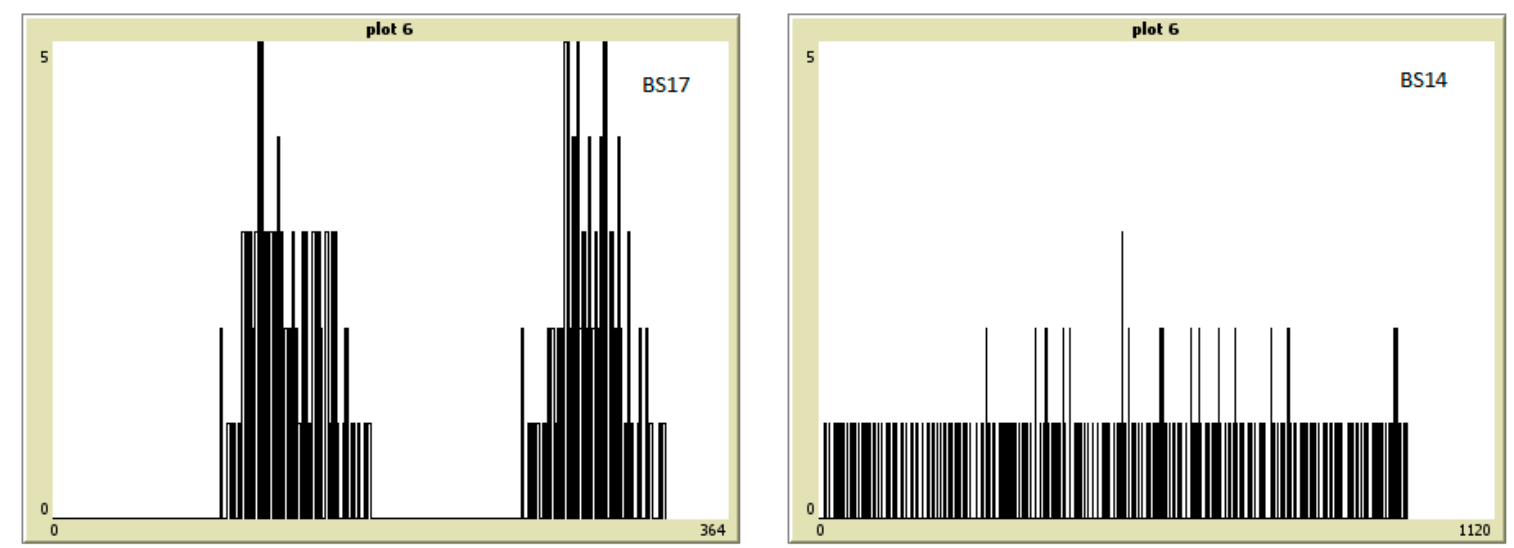

Figure 15. The histogram for the number of seat and aisle interferences (BS17 vs. BS14 method). 


\section{Conclusions}

The present paper analyses the potential influence the seat and aisle interferences might have on the overall boarding time by considering 24 boarding methods from the literature. An agent-based model has been created in which the behavior rules for each boarding method have been given to the agents. While inside the aircraft, the agents can face four types of seat interferences and/or aisle interferences.

The agent-based model in NetLogo has been run several times and a series of variables related to seat and aisle interferences have been extracted. Based on them, we have analyzed why some of the methods are performing better in terms of boarding time than other boarding methods.

It has been observed that even some of the methods face no seating interferences as a result of their boarding rules, the overall boarding time encountered in their case is good, but not best. This made us extend the analysis by including, step by step, a single factor influence into the model. For this, we have first considered the influence of the rules that are governing each type of method and we have observed that the methods starting from the rear of the aircraft produce better boarding times in the absence of seat and aisle interference.

Then, the influence of seat interferences were considered by re-running the model for each boarding method and making all the agents board without a hand luggage. This constraint imposed to the model reveled that some of the methods are scoring relatively small delay times while having a significant number of seat interferences. Thus, we have considered necessary the analysis of the interferences' number histogram over the whole simulation time and we have observed that the parallel seating and/or aisle interferences are possible in some boarding methods with a direct impact on the overall boarding time.

The results have shown that some of the best methods present either: (a) no seat interferences and aisle interferences or (b) good boarding rules (for example the one stating that the passengers' boarding should start from the back of the airplane) and aisle and seat interferences.

The method performed better than all the other methods comes with good boarding rules (back-to-front) and a higher number of parallel seat and/or aisle interferences.

Thus, when proposing a new boarding method, one should consider the use of the back-to-front rule along with the possibility of having seat or aisle interferences simultaneously in different parts of the aircraft.

For future research, we aim to test the influence of the interferences on two-door boarding situations. Also, some of the results related to the presence of the seat and aisle interferences will be considered in future research dealing with the development of new methods for airplane boarding using apron buses. Another research direction is the inclusion of a couple of passengers with reduced mobility into simulations or the consideration of the groups located in different parts of the aircraft.

The NetLogo 6.0.4 model can be accessed at the following address: https://github.com/ liviucotfas/ase-2018-sustainability-interferences.

Author Contributions: Conceptualization, C.D. and L.-A.C.; Methodology, C.D.; Software, L.-A.C.; Validation, L.C. and A.G.M.; Formal Analysis, C.D. and L.C.; Investigation, A.G.M. and L.C.; Data Curation, L.-A.C. and L.C.; Writing-Original Draft Preparation, C.D.; Writing-Review \& Editing, L.-A.C. and A.G.M.; Visualization, L.C. and A.G.M.; Supervision, C.D.

Funding: This research received no external funding.

Conflicts of Interest: The authors declare no conflict of interest. 
Appendix A. Summary of Some Boarding Rules for Different Boarding Methods

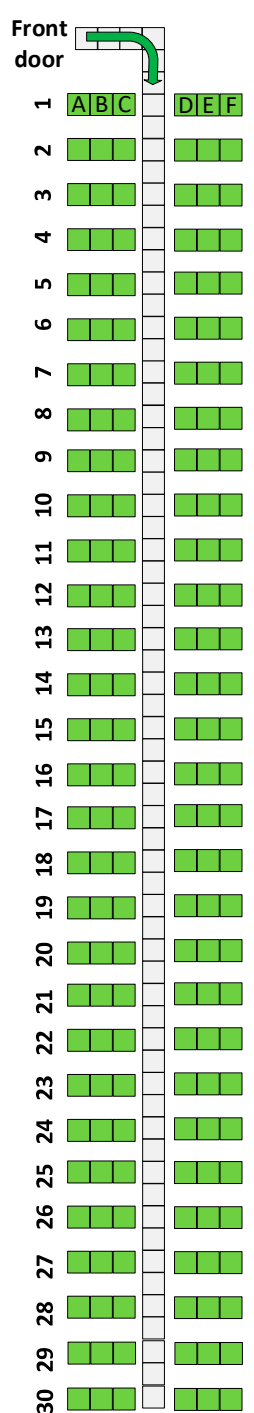

BS1

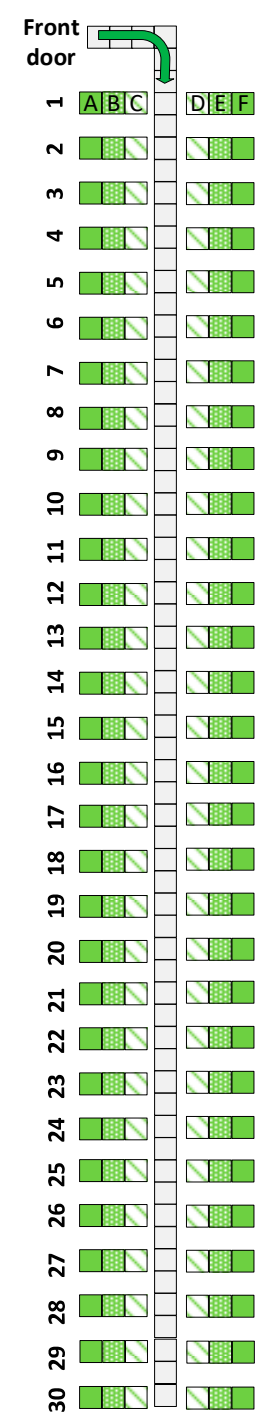

BS2

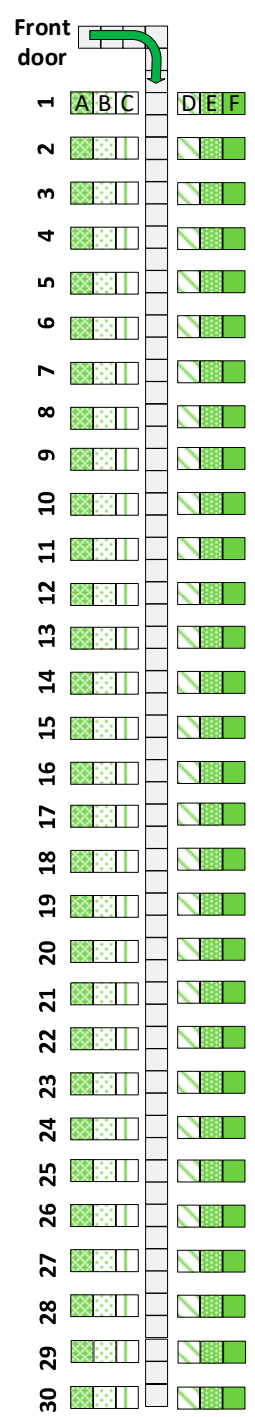

BS3

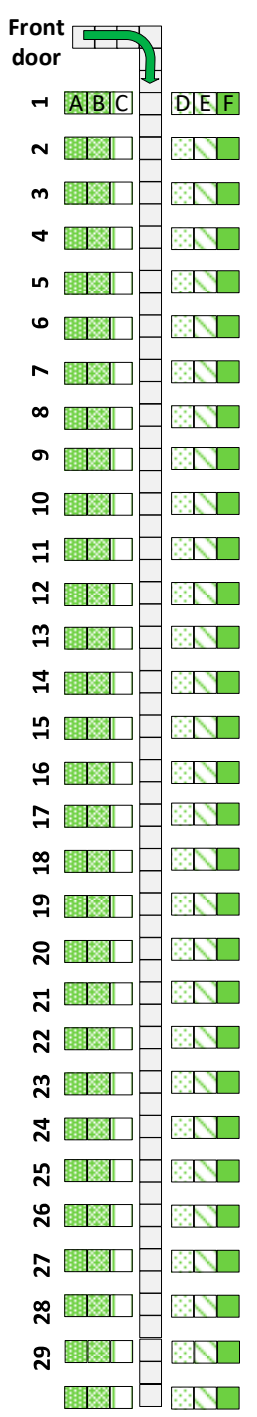

BS4

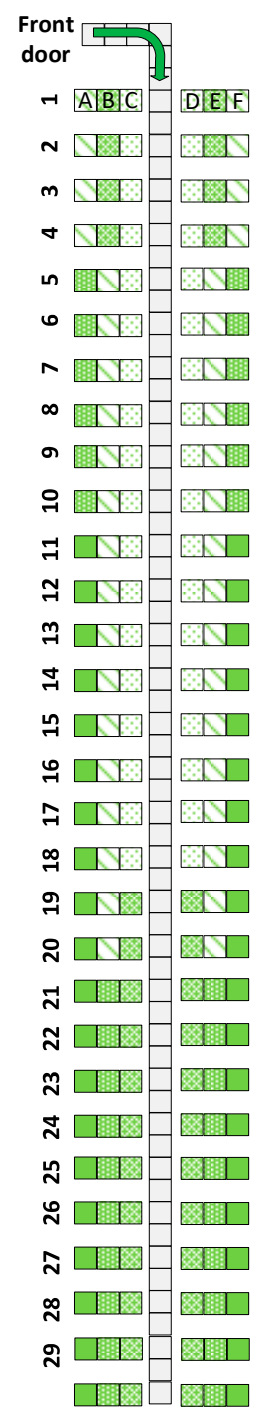

BS5

\footnotetext{
$\square$ Aisle $\quad$ Seat group $4 \quad \square$ Seat group 8

$\square$ Seat group $1 \square$ Seat group $5 \square$ Seat group 9

国 Seat group $2 \square$ Seat group $6 \square$ Seat group 10

$\square$ Seat group $3 \quad$ Seat group 7
}

Figure A1. Boarding rules for: random with assigned seat (BS1), outside-in (BS2), window to aisle half block (BS3), window to aisle alternate (BS4), reverse pyramid (BS5). 


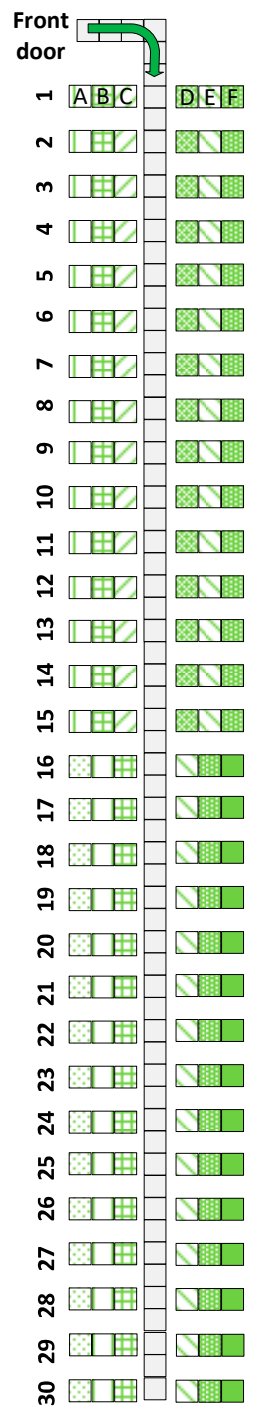

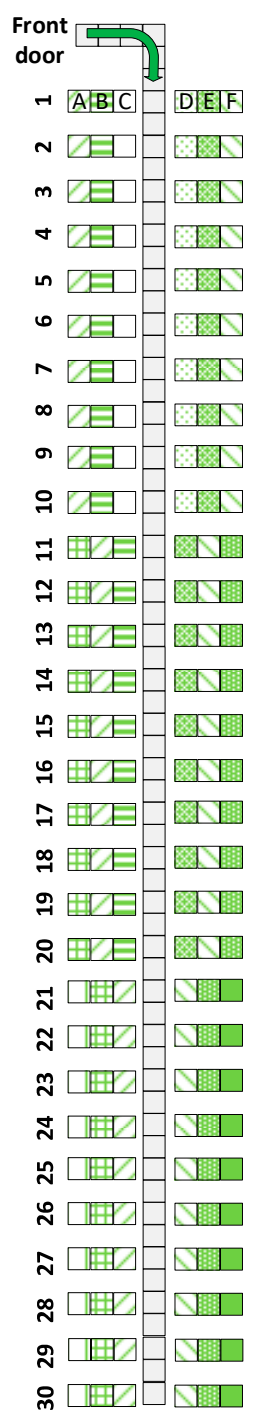

BS7

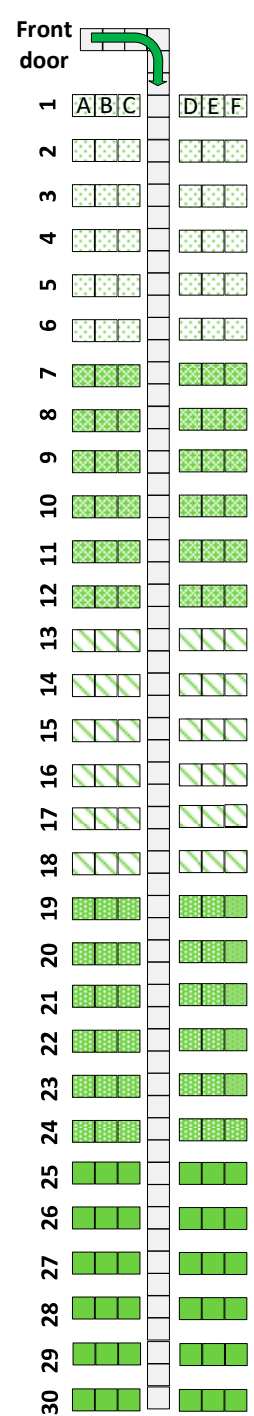

BS8

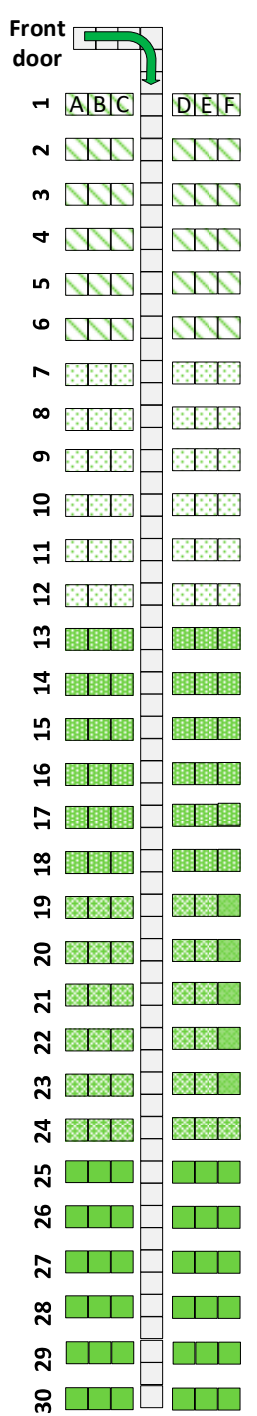

BS9

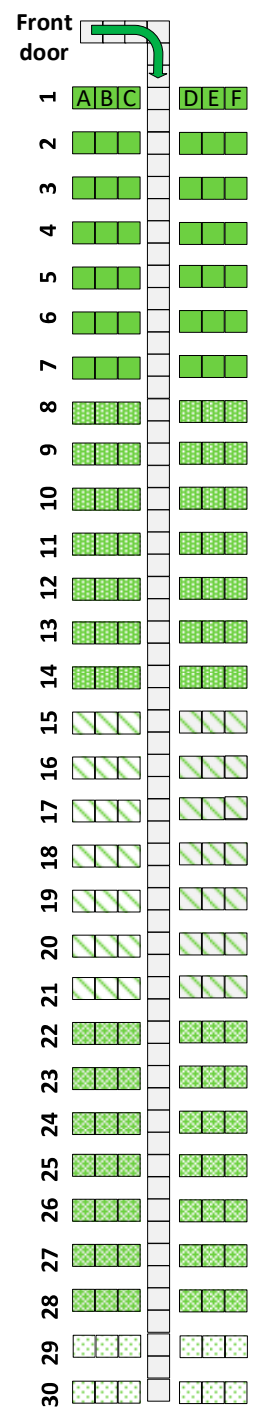

BS10
$\begin{array}{llll}\square \text { Aisle } & \text { Seat group } 4 & \square \text { Seat group 8 } \\ \square \text { Seat group 1 } & \text { Seat group } 5 & \square \text { Seat group 9 }\end{array}$
Seat group $2 \square$ Seat group $6 \square$ Seat group 10
$\square$ Seat group $3 \quad$ 困 Seat group 7

Figure A2. Boarding rules for: reverse pyramid half-zone (1) (BS6), reverse pyramid half-zone (2) (BS7), back-to-front (BS8), back-to-front mix (BS9), front-to-back (BS10).

\section{References}

1. Ren, X.; Xu, X. Experimental analyses of airplane boarding based on interference classification. J. Air Transp. Manag. 2018, 71, 55-63. [CrossRef]

2. Schmidt, M. A review of aircraft turnaround operations and simulations. Prog. Aerosp. Sci. 2017, 92, 25-38. [CrossRef]

3. Schultz, M. The Seat Interference Potential as an Indicator for the Aircraft Boarding Progress; No. 2017-01-2113; SAE Technical Paper; SAE: Warrendale, PA, USA, 2017.

4. Kierzkowski, A.; Kisiel, T. The Human Factor in the Passenger Boarding Process at the Airport. Procedia Eng. 2017, 187, 348-355. [CrossRef] 
5. Eurocontrol. All-Causes Delay and Cancellations to Air Transport in Europe-July 2017. Available online: https: / www.eurocontrol.int/sites / default/ files/publication/files / flad-july-2017.pdf (accessed on 18 October 2018).

6. Nyquist, D.C.; McFadden, K.L. A study of the airline boarding problem. J. Air Transp. Manag. 2008, 14, 197-204. [CrossRef]

7. Steiner, A.; Philipp, M. Speeding up the airplane boarding process by using pre-boarding areas. In Proceedings of the 9th Swiss Transport Research Conference, Ascona, Switzerland, 9-11 September 2009.

8. Steffen, J.H. A statistical mechanics model for free-for-all airplane passenger boarding. Am. J. Phys. 2008, 76, 1114-1119. [CrossRef]

9. Milne, R.J.; Kelly, A.R. A new method for boarding passengers onto an airplane. J. Air Transp. Manag. 2014, 34, 93-100. [CrossRef]

10. Milne, R.; Salari, M.; Kattan, L. Robust Optimization of Airplane Passenger Seating Assignments. Aerospace 2018, 5, 80. [CrossRef]

11. Steffen, J.H. Optimal boarding method for airline passengers. J. Air Transp. Manag. 2008, 14, 146-150. [CrossRef]

12. Qiang, S.-J.; Jia, B.; Xie, D.-F.; Gao, Z.-Y. Reducing airplane boarding time by accounting for passengers' individual properties: A simulation based on cellular automaton. J. Air Transp. Manag. 2014, 40, 42-47. [CrossRef]

13. Tang, T.-Q.; Yang, S.-P.; Ou, H.; Chen, L.; Huang, H.-J. An aircraft boarding model with the group behavior and the quantity of luggage. Transp. Res. Part C Emerg. Technol. 2018, 93, 115-127. [CrossRef]

14. Ferrari, P.; Nagel, K. Robustness of Efficient Passenger Boarding Strategies for Airplanes. Transp. Res. Rec. J. Transp. Res. Board 2005, 1915, 44-54. [CrossRef]

15. Tang, T.-Q.; Wu, Y.-H.; Huang, H.-J.; Caccetta, L. An aircraft boarding model accounting for passengers' individual properties. Transp. Res. Part C Emerg. Technol. 2012, 22, 1-16. [CrossRef]

16. Steffen, J.H.; Hotchkiss, J. Experimental test of airplane boarding methods. J. Air Transp. Manag. 2012, 18, 64-67. [CrossRef]

17. Van Landeghem, H.; Beuselinck, A. Reducing passenger boarding time in airplanes: A simulation based approach. Eur. J. Oper. Res. 2002, 142, 294-308. [CrossRef]

18. Van den Briel, M.H.L.; Villalobos, J.R.; Hogg, G.L.; Lindemann, T.; Mulé, A.V. America West Airlines Develops Efficient Boarding Strategies. Interfaces 2005, 35, 191-201. [CrossRef]

19. Notomista, G.; Selvaggio, M.; Sbrizzi, F.; Di Maio, G.; Grazioso, S.; Botsch, M. A fast airplane boarding strategy using online seat assignment based on passenger classification. J. Air Transp. Manag. 2016, 53, 140-149. [CrossRef]

20. Zeineddine, H. A dynamically optimized aircraft boarding strategy. J. Air Transp. Manag. 2017, 58, $144-151$. [CrossRef]

21. Bachmat, E.; Berend, D.; Sapir, L.; Skiena, S.; Stolyarov, N. Analysis of Airplane Boarding Times. Oper. Res. 2009, 57, 499-513. [CrossRef]

22. Schultz, M. Dynamic change of aircraft seat condition for fast boarding. Transp. Res. Part C Emerg. Technol. 2017, 85, 131-147. [CrossRef]

23. Bazargan, M. A linear programming approach for aircraft boarding strategy. Eur. J. Oper. Res. 2007, 183, 394-411. [CrossRef]

24. Soolaki, M.; Mahdavi, I.; Mahdavi-Amiri, N.; Hassanzadeh, R.; Aghajani, A. A new linear programming approach and genetic algorithm for solving airline boarding problem. Appl. Math. Model. 2012, 36, 4060-4072. [CrossRef]

25. Kuo, C.-C. An Improved Zero-One Linear Programming Model for the Plane Boarding Problem. In Applications of Management Science; Applications of Management Science; Emerald Group Publishing Limited: Bingley, UK, 2015; Volume 17, pp. 53-69.

26. Iyigunlu, S.; Fookes, C.; Yarlagadda, P. Agent-based Modelling of Aircraft Boarding Methods. In Proceedings of the 4th International Conference on Simulation and Modeling Methodologies, Technologies and Applications, Vienna, Austria, 28-30 August 2014; SCITEPRESS-Science and Technology Publications: Vienna, Austria, 2014; pp. 148-154.

27. Milne, R.J.; Salari, M. Optimization of assigning passengers to seats on airplanes based on their carry-on luggage. J. Air Transp. Manag. 2016, 54, 104-110. [CrossRef] 
28. Delcea, C.; Cotfas, L.-A.; Paun, R. Agent-Based Evaluation of the Airplane Boarding Strategies' Efficiency and Sustainability. Sustainability 2018, 10, 1879. [CrossRef]

29. Delcea, C.; Cotfas, L.-A.; Chiriță, N.; Nica, I. A Two-Door Airplane Boarding Approach When Using Apron Buses. Sustainability 2018, 10, 3619. [CrossRef]

30. Delcea, C.; Cotfas, L.-A.; Paun, R. Airplane Boarding Strategies Using Agent-Based Modeling and Grey Analysis. In Computational Collective Intelligence; Nguyen, N.T., Pimenidis, E., Khan, Z., Trawiński, B., Eds.; Springer International Publishing: Cham, Switzerland, 2018; Volume 11055, pp. 329-339, ISBN 978-3-319-98442-1.

31. Schultz, M. Field Trial Measurements to Validate a Stochastic Aircraft Boarding Model. Aerospace 2018, 5, 27. [CrossRef]

32. Qiang, S.; Jia, B.; Huang, Q. Evaluation of Airplane Boarding/Deboarding Strategies: A Surrogate Experimental Test. Symmetry 2017, 9, 222. [CrossRef]

33. Wilensky, U.; Rand, W. An Introduction to Agent-Based Modeling: Modeling Natural, Social, and Engineered Complex Systems with NetLogo; The MIT Press: Cambridge, MA, USA, 2015; ISBN 978-0-262-73189-8.

34. Delcea, C.; Bradea, I.A. Economic Cybernetics. An Equation-Based Modeling and Agent-Based Modeling Approach; Editura Universitara: București, Romania, 2017; ISBN 978-606-28-0629-3.

35. Gao, M.; Zhou, L.; Chen, Y. An Alternative Approach for High Speed Railway Carrying Capacity Calculation Based on Multiagent Simulation. Discret. Dyn. Nat. Soc. 2016, 2016, e4278073. [CrossRef]

36. Highland, F. Modeling Complexity in Multi-modal Adaptive Survey Systems. Procedia Comput. Sci. 2014, 36, 198-203. [CrossRef]

37. Riaz, F.; Jabbar, S.; Sajid, M.; Ahmad, M.; Naseer, K.; Ali, N. A collision avoidance scheme for autonomous vehicles inspired by human social norms. Comput. Electr. Eng. 2018. [CrossRef]

38. Vo, T.T.A.; van der Waerden, P.; Wets, G. Micro-simulation of Car Drivers' Movements at Parking Lots. Procedia Eng. 2016, 142, 100-107. [CrossRef]

39. Taboada, M.; Cabrera, E.; Iglesias, M.L.; Epelde, F.; Luque, E. An Agent-Based Decision Support System for Hospitals Emergency Departments. Procedia Comput. Sci. 2011, 4, 1870-1879. [CrossRef]

40. Prachai, S. The Design of Diabetes Simulation System using Multi-Agent. Procedia Soc. Behav. Sci. 2012, 40, 146-151. [CrossRef]

41. Pardo, M.; Coronado, W.F. Agent-based Modeling and Simulation to Adoption Process of Information Technologies in Health Systems. IEEE Lat. Am. Trans. 2016, 14, 3358-3363. [CrossRef]

42. Delcea, C.; Bradea, I.A.; Cotfas, L.A.; Scarlat, E. Opinion influence in online social media environments-U grey system theory and agent-based modeling approach. In Proceedings of the 2017 International Conference on Grey Systems and Intelligent Services (GSIS), Stockholm, Sweden, 8-11 August 2017; pp. 349-355.

43. Castilla-Rho, J.C.; Mariethoz, G.; Rojas, R.; Andersen, M.S.; Kelly, B.F.J. An agent-based platform for simulating complex human-aquifer interactions in managed groundwater systems. Environ. Model. Softw. 2015, 73, 305-323. [CrossRef]

44. West, T.A.P.; Grogan, K.A.; Swisher, M.E.; Caviglia-Harris, J.L.; Sills, E.; Harris, D.; Roberts, D.; Putz, F.E. A hybrid optimization-agent-based model of REDD+ payments to households on an old deforestation frontier in the Brazilian Amazon. Environ. Model. Softw. 2018, 100, 159-174. [CrossRef]

45. Wagner, N.; Agrawal, V. An agent-based simulation system for concert venue crowd evacuation modeling in the presence of a fire disaster. Expert Syst. Appl. 2014, 41, 2807-2815. [CrossRef]

46. Shi, J.; Ren, A.; Chen, C. Agent-based evacuation model of large public buildings under fire conditions. Autom. Constr. 2009, 18, 338-347. [CrossRef]

47. Tan, L.; Hu, M.; Lin, H. Agent-based simulation of building evacuation: Combining human behavior with predictable spatial accessibility in a fire emergency. Inf. Sci. 2015, 295, 53-66. [CrossRef]

48. Dossetti, V.; Bouzat, S.; Kuperman, M.N. Behavioral effects in room evacuation models. Phys. A Stat. Mech. Its Appl. 2017, 479, 193-202. [CrossRef]

49. Malinowski, A.; Czarnul, P.; Czurylo, K.; Maciejewski, M.; Skowron, P. Multi-agent large-scale parallel crowd simulation. Procedia Comput. Sci. 2017, 108, 917-926. [CrossRef]

50. Oğuz, O.; Akaydın, A.; Yılmaz, T.; Güdükbay, U. Emergency crowd simulation for outdoor environments. Comput. Graph. 2010, 34, 136-144. [CrossRef]

51. Shendarkar, A.; Vasudevan, K.; Lee, S.; Son, Y.-J. Crowd simulation for emergency response using BDI agents based on immersive virtual reality. Simul. Model. Pract. Theory 2008, 16, 1415-1429. [CrossRef] 
52. Vermuyten, H.; Beliën, J.; De Boeck, L.; Reniers, G.; Wauters, T. A review of optimisation models for pedestrian evacuation and design problems. Saf. Sci. 2016, 87, 167-178. [CrossRef]

53. Abdelghany, A.; Abdelghany, K.; Mahmassani, H.; Alhalabi, W. Modeling framework for optimal evacuation of large-scale crowded pedestrian facilities. Eur. J. Oper. Res. 2014, 237, 1105-1118. [CrossRef]

54. Chooramun, N.; Lawrence, P.J.; Galea, E.R. An agent based evacuation model utilising hybrid space discretisation. Saf. Sci. 2012, 50, 1685-1694. [CrossRef]

55. Ha, V.; Lykotrafitis, G. Agent-based modeling of a multi-room multi-floor building emergency evacuation. Phys. A Stat. Mech. Its Appl. 2012, 391, 2740-2751. [CrossRef]

56. Delcea, C.; Cotfas, L.-A.; Paun, R. Agent-Based Optimization of the Emergency Exits and Desks Placement in Classrooms. In Computational Collective Intelligence; Nguyen, N.T., Pimenidis, E., Khan, Z., Trawiński, B., Eds.; Springer International Publishing: Cham, Switzerland, 2018; Volume 11055, pp. 340-348, ISBN 978-3-319-98442-1.

(C) 2018 by the authors. Licensee MDPI, Basel, Switzerland. This article is an open access article distributed under the terms and conditions of the Creative Commons Attribution (CC BY) license (http:/ / creativecommons.org/licenses/by/4.0/). 